medRxiv preprint doi: https://doi.org/10.1101/2021.09.25.21264106; this version posted September 28 , 2021. The copyright holder for this preprint (which was not certified by peer review) is the author/funder, who has granted medRxiv a license to display the preprint in perpetuity.

All rights reserved. No reuse allowed without permission.

\title{
Functional Data Analysis: Transition from Daily Observation of COVID-19 Prevalence in France to Functional Curves
}

1 Laboratory AGEIS EA 7407, Team Tools for e-Gnosis Medical \& Labcom CNRS/UGA/OrangeLabs Telecom4Health, Faculty of Medicine, University Grenoble Alpes (UGA), 38700 La Tronche, France; Kayode.Oshinubi@univ-grenoble-alpes.fr, firas_ibrahim11@hotmail.com, Mustapha.Rachdi@, univ-grenoble-alpes.fr, Jacques.Demongeot@univ-grenoble-alpes.fr * Correspondence: Jacques.Demongeot@univ-grenoble-alpes.fr

\begin{abstract}
In this paper we use the technique of functional data analysis to model daily hospitalized, deceased, ICU cases and return home patient numbers along the COVID-19 outbreak, considered as functional data across different departments in France while our response variables are numbers of vaccinations, deaths, infected, recovered and tests in France. These sets of data were considered before and after vaccination started in France. We used some smoothing techniques to smooth our data set, then analysis based on functional principal components method was performed, clustering using k-means techniques was done to understand the dynamics of the pandemic in different French departments according to their geographical location on France map and we also performed canonical correlations analysis between variables. Finally, we made some predictions to assess the accuracy of the method using functional linear regression models.
\end{abstract}

Keywords: Canonical correlation, clustering, COVID-19, prediction, functional data analysis, functional principal components analysis, functional linear regression

\section{Introduction}

\subsection{Background and literature review}

The modeling of COVID-19 pandemic across the globe has been approached using different techniques in mathematics and statistics by different researchers but the use of functional data analysis (FDA) has been done by few scientists. Functional data analysis is useful in many fields such as medical sciences, biology, statistical analysis and econometrics while several books like [1] have treated the theoretical aspects and methodology and more recently, researchers have dealt with FDA application to COVID-19 modeling [2-4].

The COVID-19 pandemic is still evolving in France as there has been three waves with possibility of a fourth wave due to a more contagious variant (Delta variant) which may lead to another lockdown following three lockdowns alongside with several non-pharmaceutical measures to mitigate the spread of the diseases. France has a total of 5,911,601 cases as at 22/07/2021, 111,554 deaths representing $2 \%$ of the total cases, 5,162,757 having recovered from the disease representing $98 \%$ of the total cases and 637,290 currently infected patients with $637,431(99.9 \%)$ in mild condition while $859(0.1 \%)$ are in critical condition.

Some researchers have worked on French public data on COVID-19 evolution in France which we shall point out few as there are many more. The robust phenomenological approach to France COVID-19 data was investigated by [14] and a new method to calculate the cumulative cases in France was proposed which illustrates the epidemic and endemic nature of the virus infection in France. [13] used methods like principal component analysis, generalized additive model and hierarchical ascendant classification to study the impacts of population age structure, epidemic spread and transmission mitigation policies on COVID-19 morbidity or mortality heterogeneity in France. [15] used ARIMA models with different parameters to forecast the spread of COVID-19 across nine countries in Europe, Asia and American continents and the study deduced that the method is useful for the prediction of the pandemic at different stages.

NOTE: This preprint reports new research that has not been certified by peer review and should not be used to guide clinical practice. Some recent works use functional data analysis for the modelling of COVID-19 pandemic as follows: [2] applied functional data analysis to United States data by using FCPA (Functional 
Principal Component Analysis) and FCCA (Functional Canonical Correlation Analysis) tools and they finally use functional time series to fit the cumulative confirmed cases in the United States and make forecasts based on the dynamics of FPCA. [3] worked on the imputation of missing data of COVID-19 hospitalized and intensive care curves in Spain regions. They used functionon-function regression technique to estimate missing values and Canonical Correlation Analysis was performed to interpret the relationship between hospital occupancy rate and illness response variables. The shapes of an epidemic curve using functional data analysis to characterize COVID19 in Italian regions and their association with mobility, positivity, socio-demographic structure and environmental covariates was worked on by [4]. The researchers have used different methods of functional data analysis like function-on-function regression techniques, clustering methods and smoothing techniques for the functional data considered.

\subsection{Time series and curve fitting}

Figure 1a gives the time series of recent daily cases of COVID-19 in France which shows stationarity with rolling values (window $=12$ ) appearing to be varying slightly. Also, the statistics are smaller than the $5 \%(p$-value $=0.02)$ critical values so we can say with $95 \%$ confidence that this is a stationary series. Also, in Figure 1c we plotted three French departments (Nord, Paris and Essonne) with more prevalent COVID-19 hospitalization cases and Figure 1d shows the fitness curve of two of the French departments (Paris and Seine-Maritime) while all departments have root mean square error in the interval $0.51 \leq R M S E \leq 17.38$ with Essonne department having the highest RMSE and Lozère department having the lowest RMSE. We present other RMSE values in Table 1. We present also (Figure 1b) a deep learning forecasting result using Gated Recurrent Units (GRU) for France data between the beginning of the pandemic in France till September 32021 by training $80 \%$ of the data and testing $20 \%$. The predicted cases curve values decline over the whole-time. In Appendix B, we present the spectral analysis of the time series in Figure 15 in order to study the periodicity of the new cases of COVID-19 in France and to present a smoothed version without noise of the data.

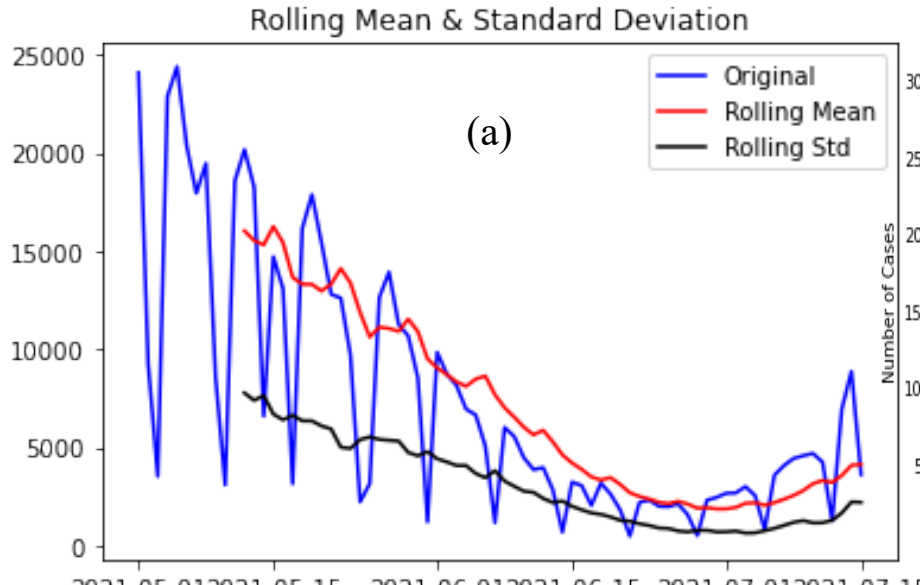

2021-05-012021-05-15 2021-06-012021-06-15 2021-07-012021-07-15
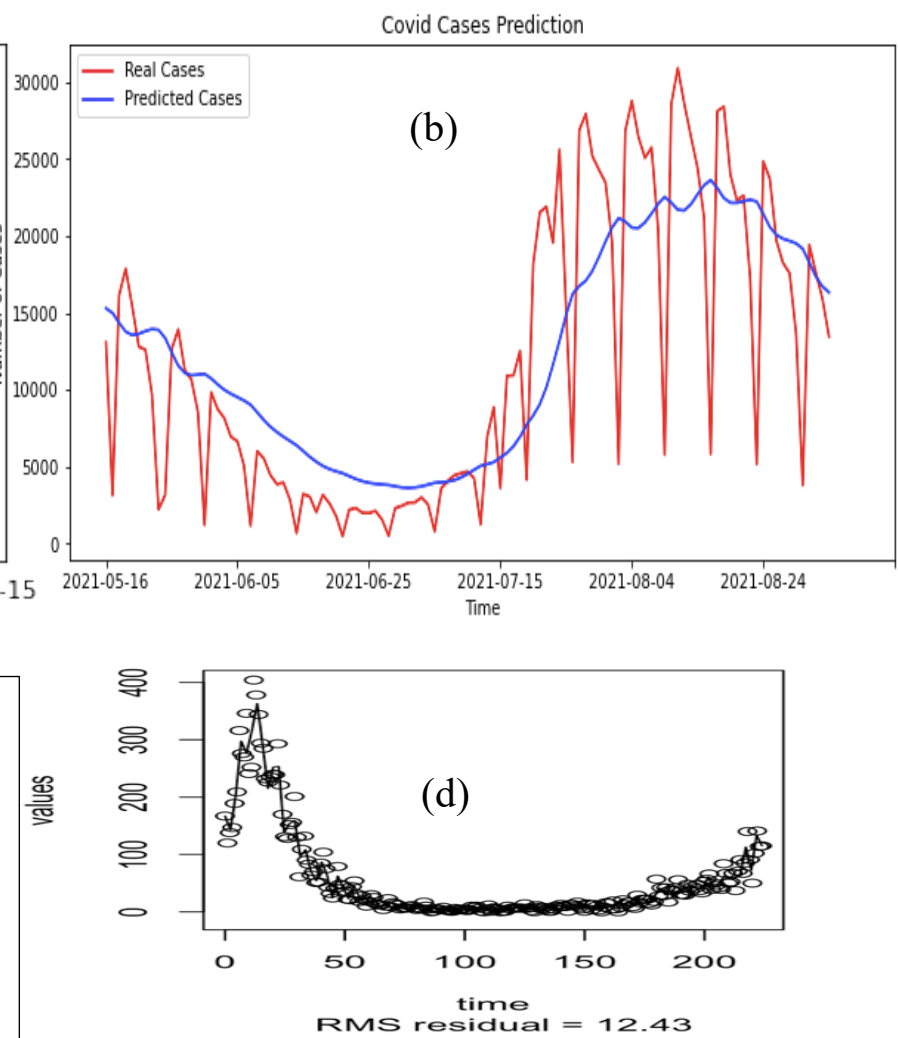

RMS residual $=1243$

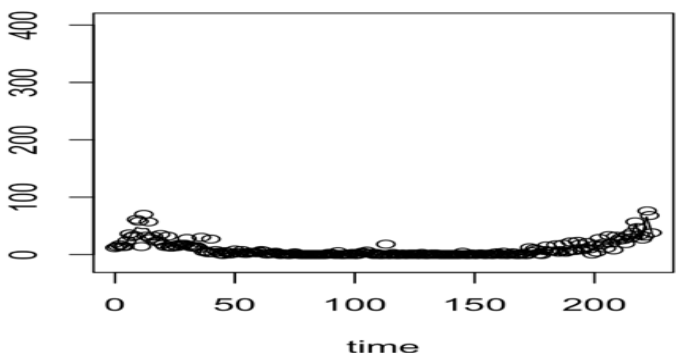


Figure 1. (a) Time series modelling of daily new cases between 01/05/2021 to 15/07/2021 in France. (b) GRU deep learning forecasting method for daily new cases between 25/02/2020 to 03/09/2021 in France. (c) Daily hospitalization cases in three French departments: Nord, Paris and Essonne. (d) Fit curve for hospitalization cases in Paris and Seine-Maritime.

Table 1. RMSE confidence interval for all French departments for the fitness curve of the four functional data

\begin{tabular}{|c|c|c|}
\hline \multicolumn{2}{|c|}{ RMSE before vaccination started } & RMSE after vaccination has started \\
\hline \hline Hospitalized & $0.51 \leq R M S E \leq 17.38$ & $1.00 \leq R M S E \leq 18.00$ \\
\hline ICU & $0.05 \leq R M S E \leq 2.60$ & $0.35 \leq R M S E \leq 5.20$ \\
\hline \hline Daily return home & $0.25 \leq R M S E \leq 12.40$ & $1.10 \leq R M S E \leq 17.50$ \\
\hline \hline Daily deceased & $0.04 \leq R M S E \leq 4.52$ & $0.32 \leq R M S E \leq 4.10$ \\
\hline
\end{tabular}

The aim of this paper is to model the prevalence of the virus in France by using several functional techniques like FCCA, K-means clustering and FPCA and to finally make some predictions about the evolution of the disease in France. The analysis was done using both Python and R packages. We considered as functional variables numbers of ICU cases, daily deceased, daily return home and hospitalization which are given as $X_{1}, X_{2}, X_{3}$ and $X_{4}$. Our response variables given as $Y_{1}, Y_{2}, Y_{3}, Y_{4}, Y_{5}$ and $Y_{6}$ are numbers of recovery, deaths, infected, vaccination, vaccination per 1000 population and number of tests. We collated data from [10], [11] and [12]. The paper is divided as follows: in Section 2 we describe the various smoothing methods employed in the analysis of the shapes of the functional data used and in Section 3 we present the functional principal components analysis results and their interpretation to the dynamics of COVID-19 prevalence in French departments, Section 4 is dedicated to the result of canonical correlation of the variables. In Section 5 we present the clustering result using K-means method and how it appears on the map of France, In Section 6 we made some predictions for some response variables and also performed the function-on-function linear regression and finally in Section 7 we opened up some perspectives and gave conclusion of the analyses.

\section{Data smoothing}

The first step in analyzing functional data is to smooth the curves. In this Section we use different smoothing techniques which we shall illustrate and give some basic explanation of the techniques we deployed for smoothing our functional data. We plotted the mean of the data set and the cross-sectional mean, which corresponds to the karcher-mean under the $\mathbb{L}^{2}$ distance [8]. We used the elastic_mean(fd) and $f$ d.mean tool in Python to do the plotting of Figure 2.

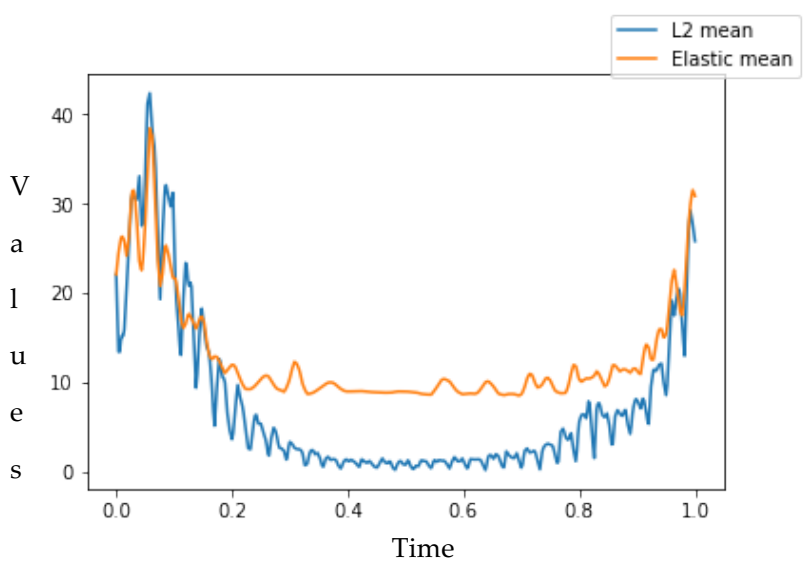

(a)

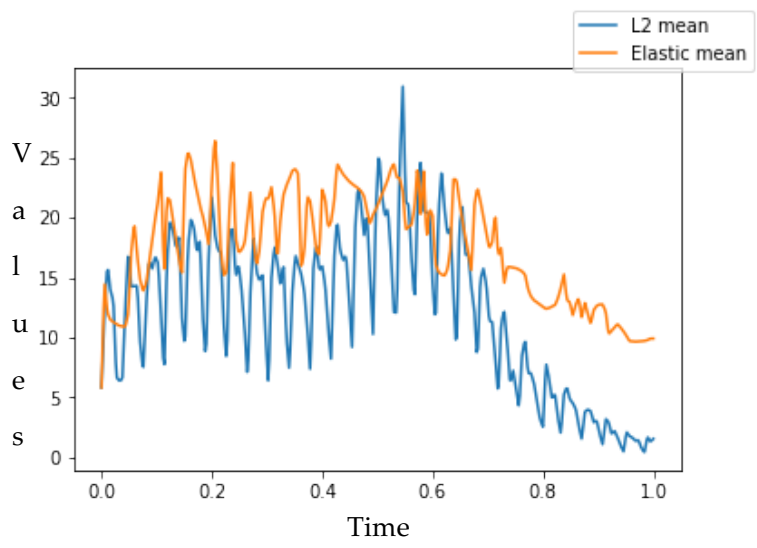

(b) 
medRxiv preprint doi: https://doi.org/10.1101/2021.09.25.21264106; this version posted September $28,2021$. The copyright holder for this preprint (which was not certified by peer review) is the author/funder, who has granted medRxiv a license to display the preprint in

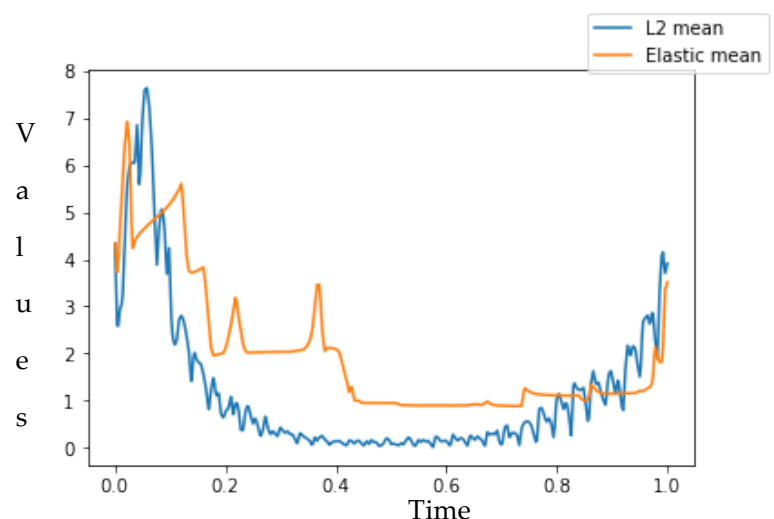

(c)

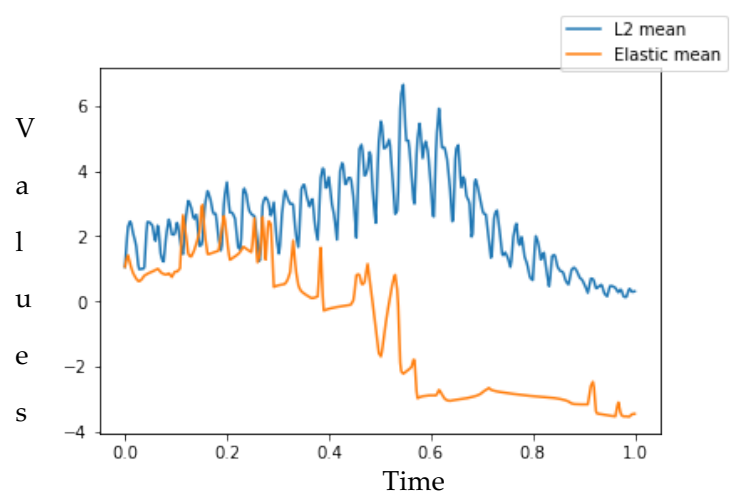

(d)

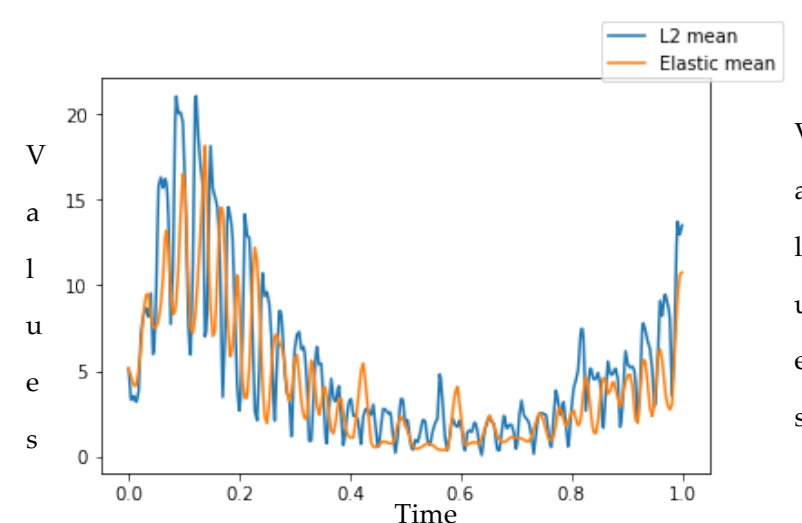

(e)

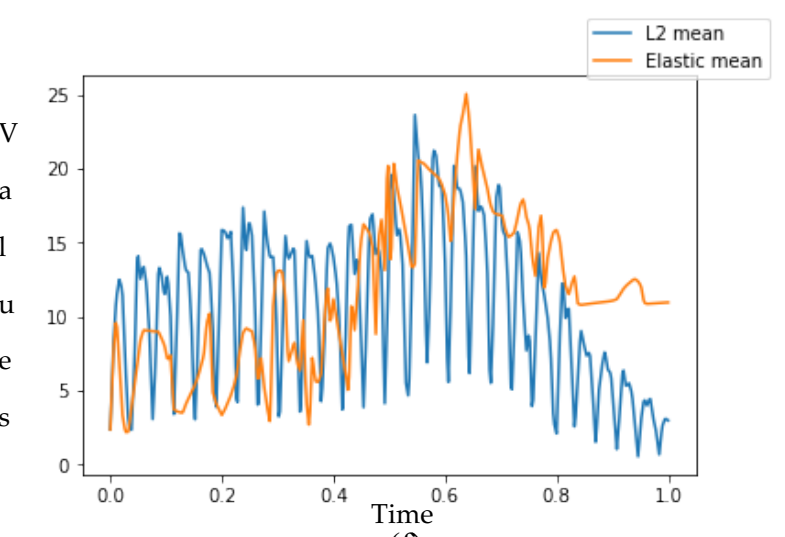

(f)

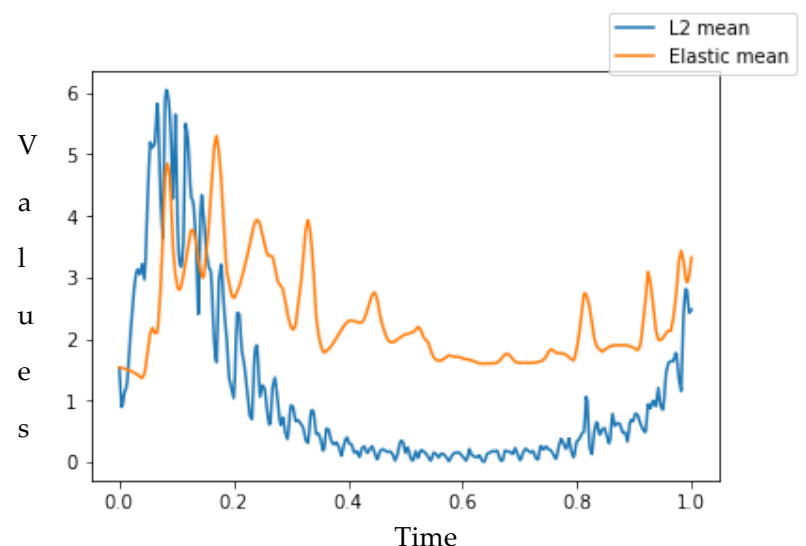

(g)

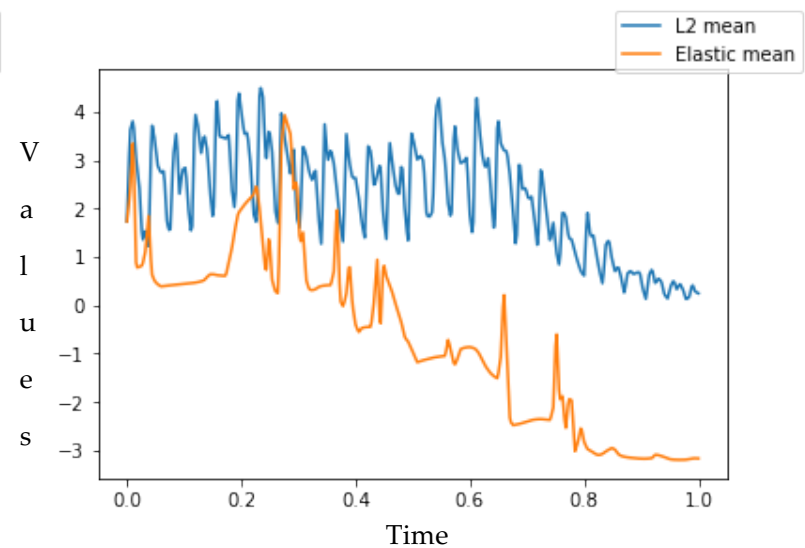

(h)

Figure 2. L2 (blue) and elastic (yellow) means of the functional data: (a) hospitalized cases, (b) hospitalized when vaccination has started, (c) ICU cases, (d) ICU cases when vaccination has started, (e) daily return home, (f) daily return home when vaccination has started, (g) daily deceased and (h) daily deceased when vaccination has started. 
medRxiv preprint doi: https://doi.org/10.1101/2021.09.25.21264106; this version posted September 28, 2021. The copyright holder for this preprint (which was not certified by peer review) is the author/funder, who has granted medRxiv a license to display the preprint in perpetuity.

All rights reserved. No reuse allowed without permission.

We observed that the elastic mean better captures the geometry of the curves compared to the standard L2 mean for some of the functional data set we considered, since it is not affected by the deformations of the curves. This phenomenon can be seen in Figures 2a, 2b, 2c, 2e, 2f and 2g, Figures $2 \mathrm{~d}$ and $2 \mathrm{~h}$ showing a bad shape for elastic mean.

\section{B-Spline smoothing technique}

B-spline technique is one of the tools used in smoothing a functional data and this can be done by changing the number of elements $(\mathrm{n}=2,3,4, \ldots)$ in the basis functions [9]. Sometimes one can use the Fourier basis for the functions to further see the variations in the curves. We give a mathematical expression on the basis functions below:

$$
f(t)=\sum_{j=1}^{n} b_{j} \propto_{j}(t)
$$

For this analysis we choose $\mathrm{n}=7$ as our number of elements and the tool in Python named basis.BSpline was used to perform the plotting of the functional data. The result of this smoothing technique can be seen in Figure 3.

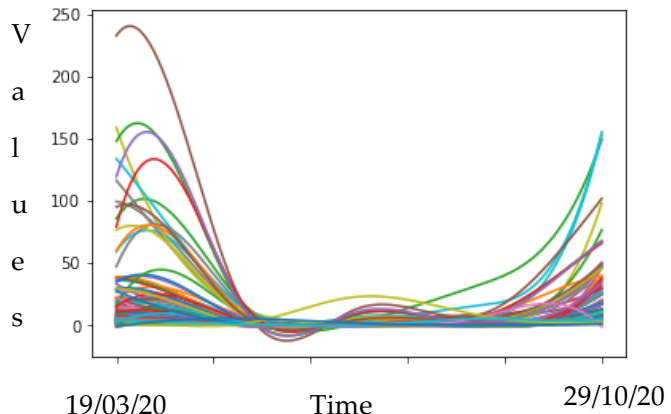

(a)

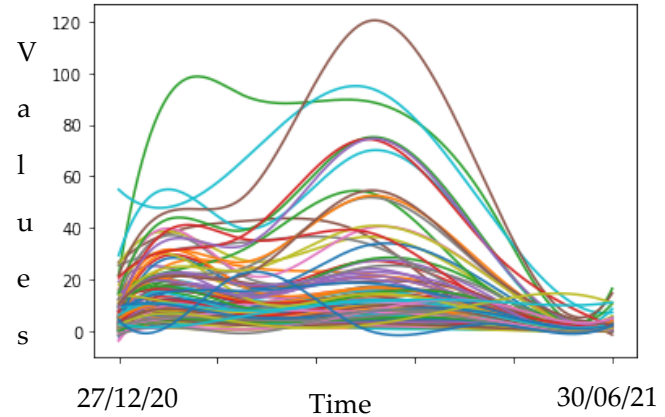

(b)

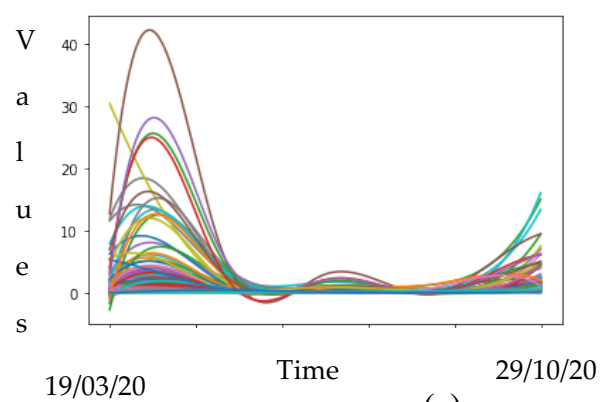

(c)

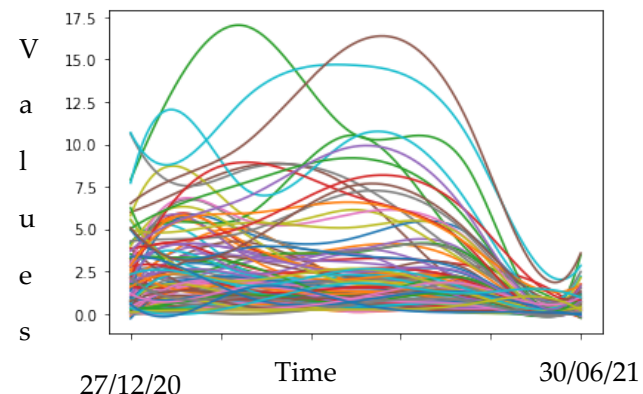

(d)

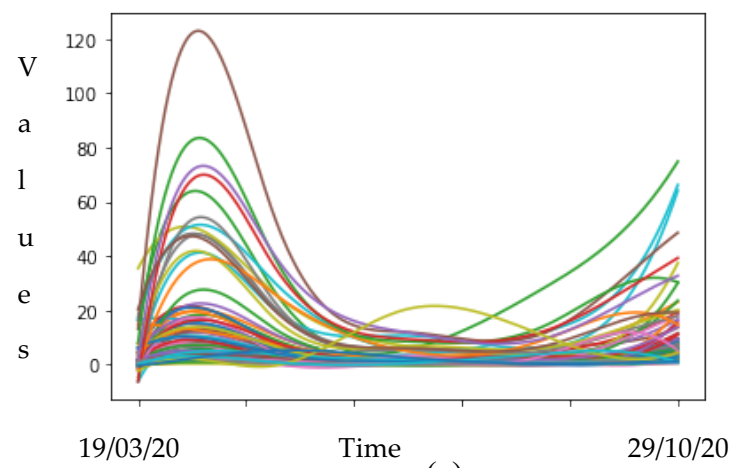

(e)

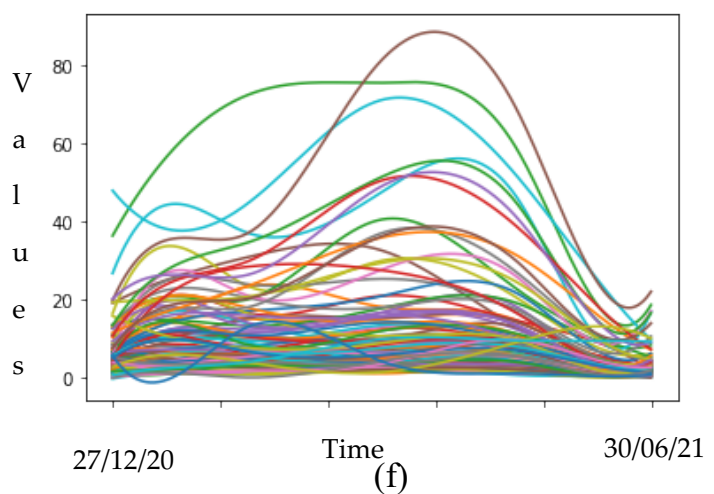

(f) 


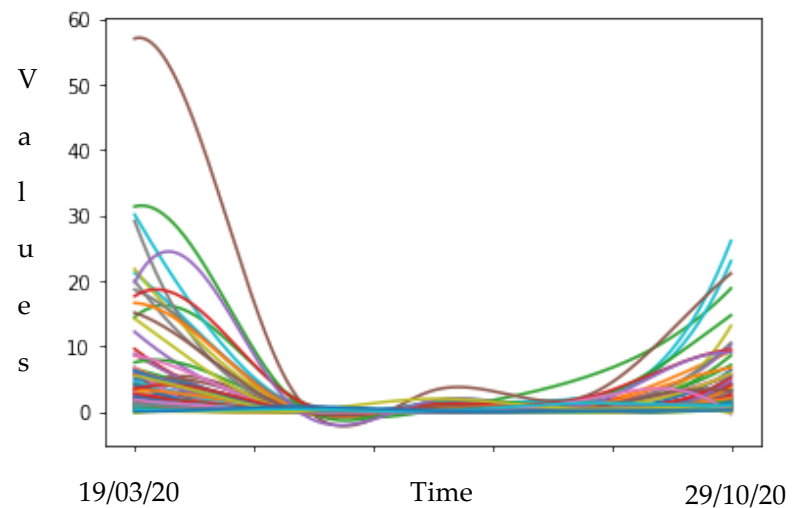

(g)

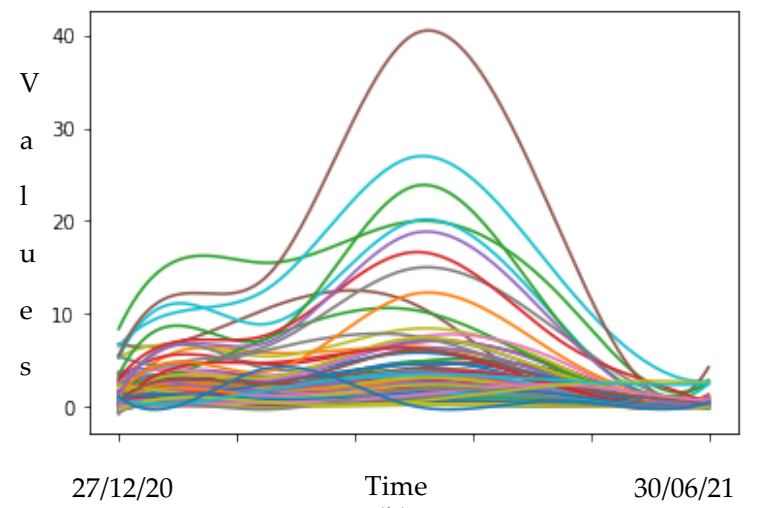

(h)

Figure 3. Smoothed curves for the shape of COVID-19 epidemic in all departments in France: ((a) hospitalized cases, (b)

In Appendix A Figure 14, we presented the correlation coefficient between all the departments in France based on the functional data in consideration, in order to see how well our data is well correlated between the departments and it was observed that there is a high correlation between various departments with except in few cases where we observed low correlation as we can see in the contour plots presented in Figures 14a to $14 \mathrm{~h}$.

\section{Smooth interpolation and monotone cubic spline interpolation}

We used spline interpolation of order 3 and then smooth the interpolation using the smoothness parameter equal to 1.5 in the cubic spline smoothing. This technique is demonstrated using interpolation and smoothness_parameter package in Python. We also use the monotone technique and a piecewise cubic Hermite interpolating polynomial (PCHIP) using a Python package called monotone. We present some of the results on Figure 4.

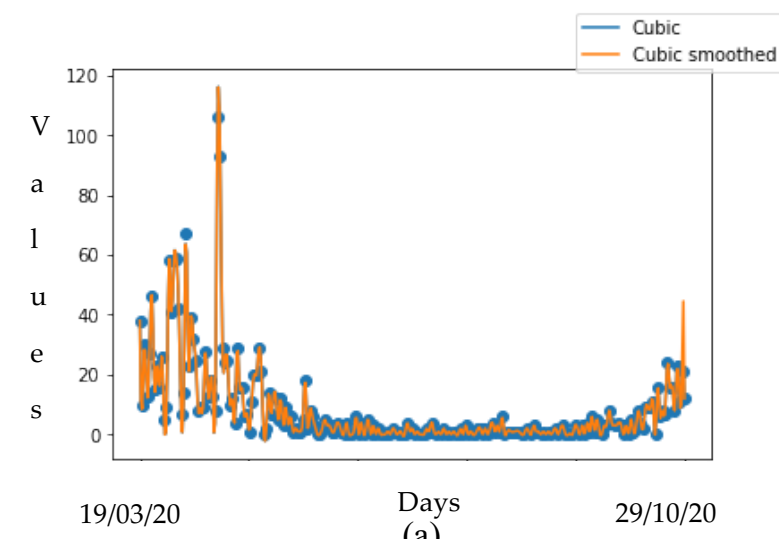

(a)

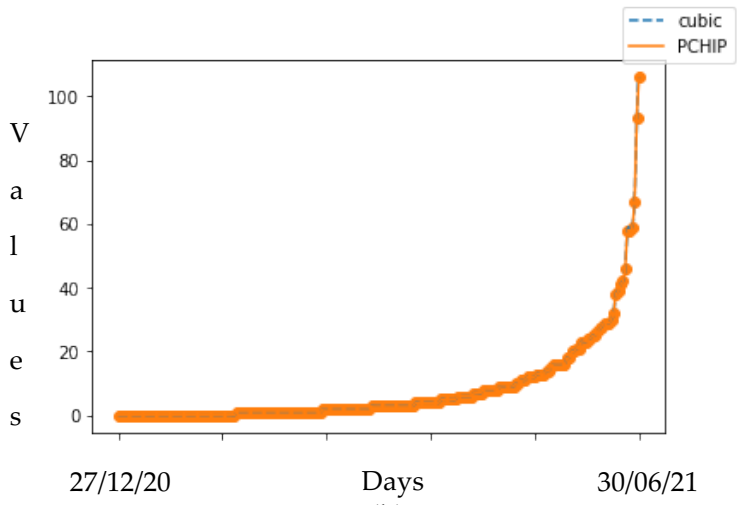

(b) 


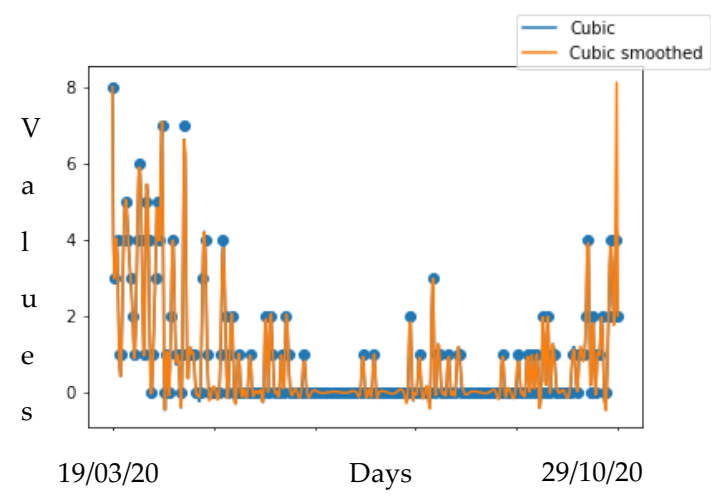

(c)

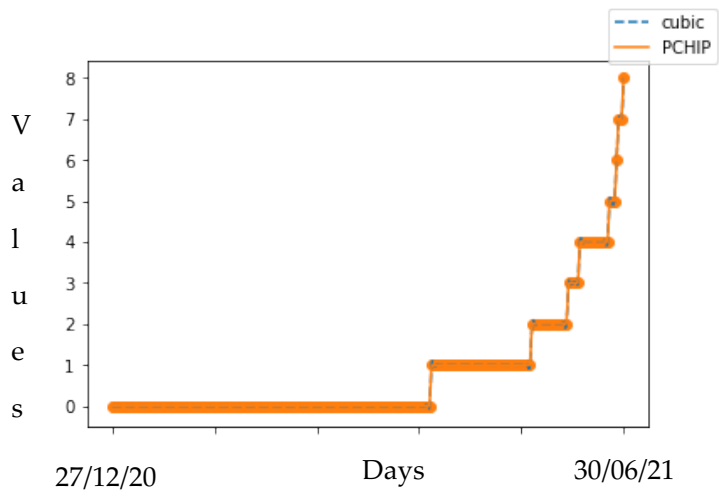

(d)

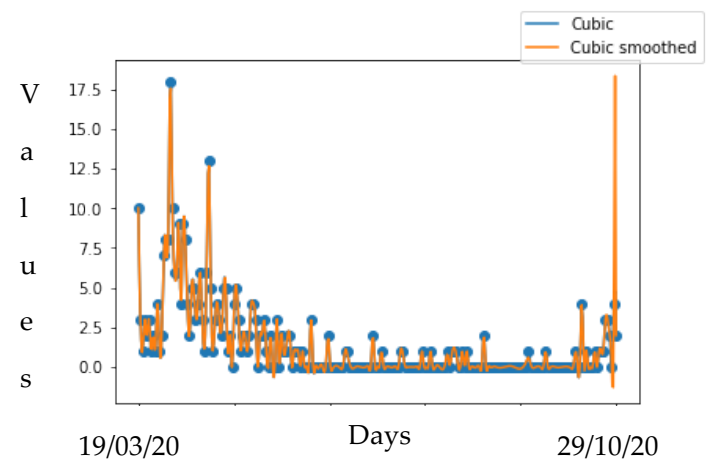

(e)

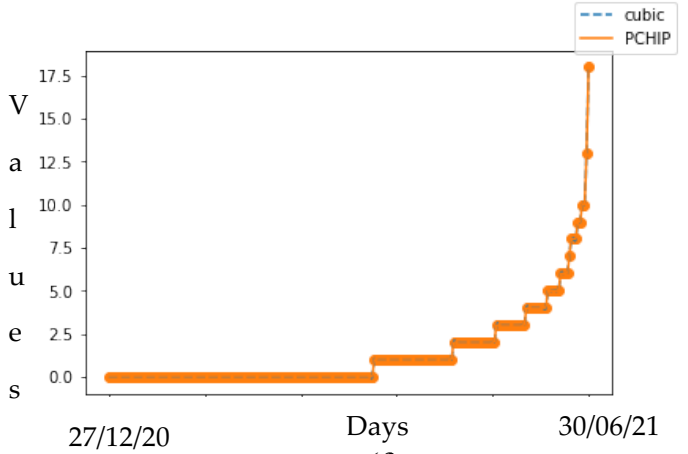

(f)

Figure 4. (a) Hospitalized cases interpolation smoothing, (b) hospitalized monotone smoothing, (c) ICU cases interpolation smoothing, (d) ICU cases monotone smoothing, (e) daily deceased interpolation smoothing and (f) daily deceased monotone smoothing.

From graphs presented in Figure 4 one can deduce that cubic spline smoothing curves exhibit oscillations and oscillations are important to know the low and high data thresholds in case the consecutive data points experience a significant change in slope. We also observed that PCHIP is smooth and non-oscillatory despite some sharp increase as the U-shape of the curve deepens.

\section{Kernel smoothing}

We also performed Kernel smoothing to show how cross validation score varies over a range of different parameters used in the smoothing methods. The essence of this section is to estimate the smoothing parameter $h$ that better represents the functional data and this smoothing parameter was selected by generalised cross-validation criteria. The non parametric method of smoothing for the functional data is based on smoothing matrix $\mathrm{M}$ given below:

$$
\begin{gathered}
m_{i j}=\frac{1}{h} K\left(\frac{t_{i}-t_{j}}{h}\right), \\
M(h)=\left(s_{j}\left(t_{i}\right)\right)=\frac{K\left(\frac{t_{i}-t_{j}}{h}\right)}{\sum_{k=1}^{T} K\left(\frac{t_{k}-t_{j}}{h}\right)},
\end{gathered}
$$

where $\mathrm{K}()$ is the Kernel function.

We plotted on Figure 5 the smoothed curves of the functional data set for three different smoothing methods and also show the scores through generalised cross-validation (GCV) for these different smoothing methods. The results show a comparable behavior of these scores by varying the smoothing parameter $h$. 
medRxiv preprint doi: https://doi.org/10.1101/2021.09.25.21264106; this version posted September 28, 2021. The copyright holder for this preprint (which was not certified by peer review) is the author/funder, who has granted medRxiv a license to display the preprint in perpetuity.

All rights reserved. No reuse allowed without permission.

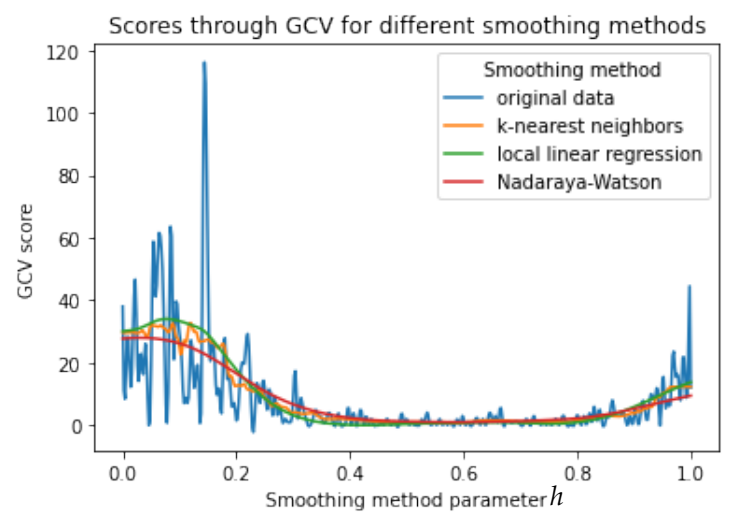

(a)

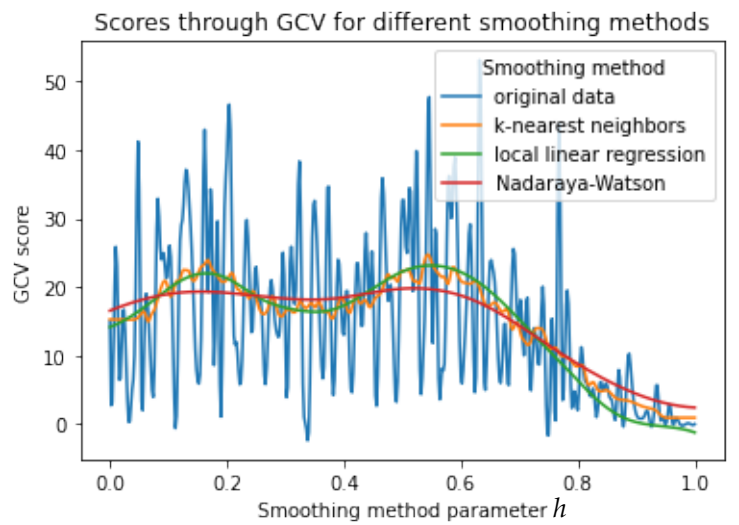

(b)

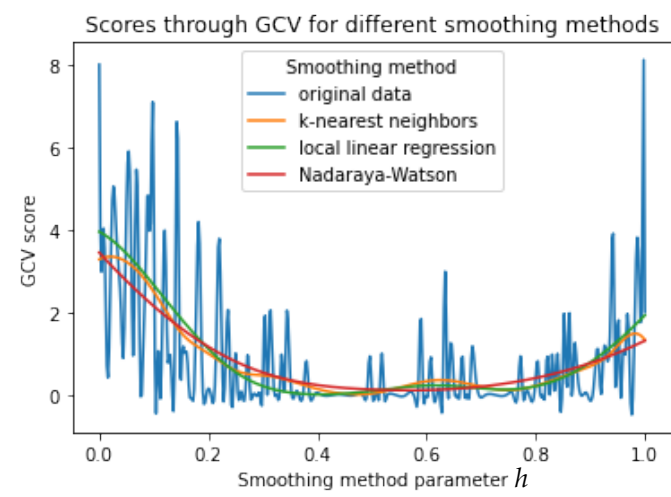

(c)

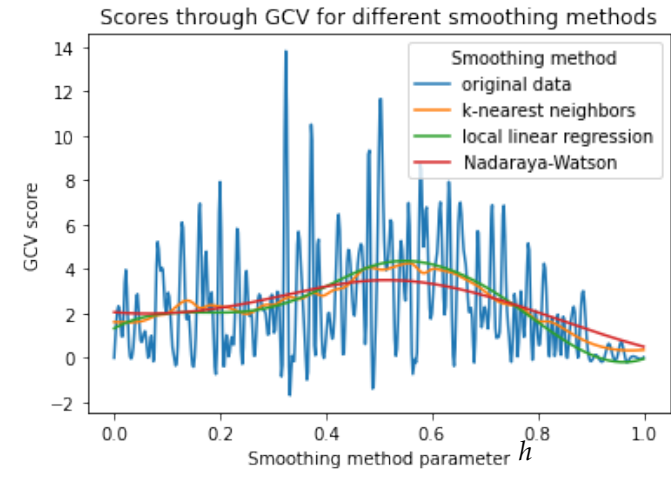

(d)

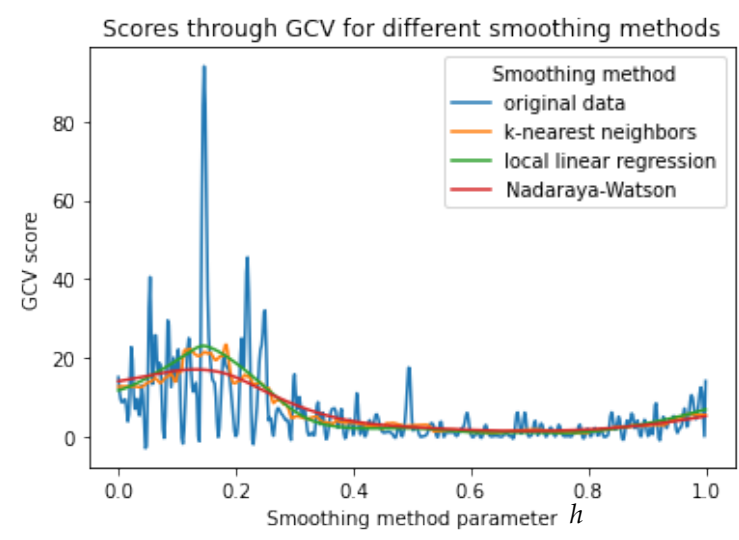

(e)

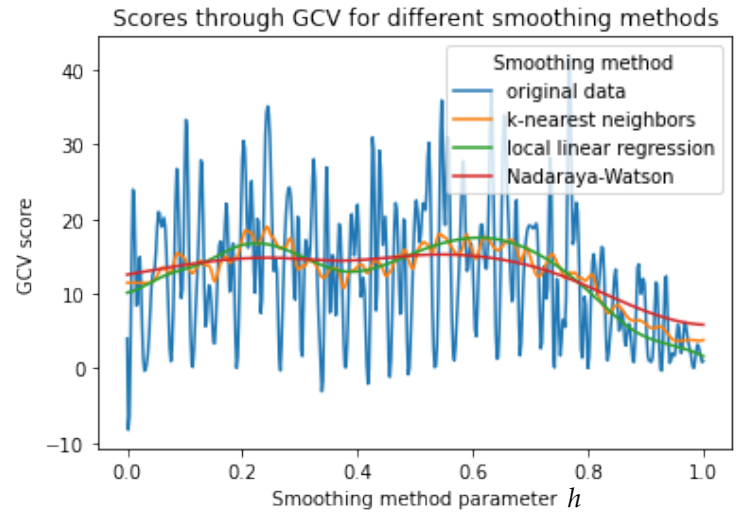

(f)

Figure 5. Kernel smoothing method for (a) hospitalized cases, (b) hospitalized when vaccination has started, (c) ICU cases, (d) ICU cases when vaccination has started, (e) daily return home and (f) daily return home when vaccination has started. 


\section{Functional principal component analysis (FPCA)}

Principal component analysis is a dimension reduction analysis tool in multivariate statistics while functional principal component analysis (FPCA) is a dimension reduction with high variance in functional data analysis [6], [7]. Let $x_{i}(t)$ be a given set of functions and let $\alpha$ be a weight, FPCA is computed as follows:

- It finds the principal component weight function $\alpha_{1}(t)$ for which the principal component score is given by

$$
f_{j 1}=\int \alpha_{1}(t) x_{i}(t) d t
$$

while maximizing $\sum_{j} f_{i 1}^{2}$ is subjected to

$$
\int \alpha^{2}(t) d t=\left\|\alpha_{1}\right\|^{2}=1
$$

- Next, the weight function $\alpha_{2}(t)$ is computed and the principal component score maximizes $\sum_{j} f_{i 2}^{2}$, and is subject to the constraint $\left\|\alpha_{2}\right\|^{2}=1$ and to the additional constraint

$$
\int \alpha_{2}(t) \alpha_{1}(t) d t=0
$$

- Then, the process is repeated for as many iterations.

In our analysis we used a tool called pca.fd for the principal component analysis. We present in this Section the 4 PCs values plot throughout the days considered and the principal component scores plot for all the different departments providing functional data being before vaccination started and during vaccination.

\section{Functional PCs}

\section{- Hospitalization cases}

In Figure 6a we observed that PC1 peaked in the early days of the pandemic between February and March 2020 and then there was a decline after about 50 days becoming stationary till day 150 possibly due to mitigation measures promulgated during this period. The same phenomenon has been observed for PC 2. In Figure 6a, PC 4 shows a sinusoidal shape, peaked at day 100 which is around June 2020 with least values at day 30 and day 180 which are respectively in March and August 2020. Figure 6b shows the same sinusoidal shape for PC 4 and same shape for PC 3 but with a drift in the observation with a difference between the dynamics of hospitalization cases before and after vaccination has started in France. PC 1 in Figure $6 \mathrm{~b}$ shows a decline across the infective period which may be due to the aggressive vaccination campaign in the country.

\section{- ICU cases}

In Figure 6c we observed that from day 50 (around April 2020) till day 150 (around July 2020), the PC 1 value which is the major PC is stable throughout this period of various confinement measures in France and all PCs tend to show increasing behavior after the confinement measures have been relaxed and in Figure 6d, PC 1 has strictly positive values while PC 2, PC 3, PC 4 show negative values between February to June 2021.

\section{- Daily return home}

In Figure 6e PC 1 peaked with a positive value at the beginning of the pandemic in France which validates the percentage of recovery as presented in the introduction Section while PC1 in Figure $6 f$ shows a positive decline across the days considered, with a disparity between the period of vaccination and without vaccination.

- Daily deceased

On the $y$-axis of Figures $6 \mathrm{~g}$ and $6 \mathrm{~h}$, we observe that this is the only result with low values for the PCs because the deaths due to COVID-19 in France remain at a low level, while all PCs show almost the same pattern as that observed in previously for the other variables. 
medRxiv preprint doi: https://doi.org/10.1101/2021.09.25.21264106; this version posted September 28 , 2021. The copyright holder for this preprint (which was not certified by peer review) is the author/funder, who has granted medRxiv a license to display the preprint in perpetuity.

All rights reserved. No reuse allowed without permission.

In Table 2, we present the PCs variance proportion and we observe that PC 1 is the most important PC.

221

222

223

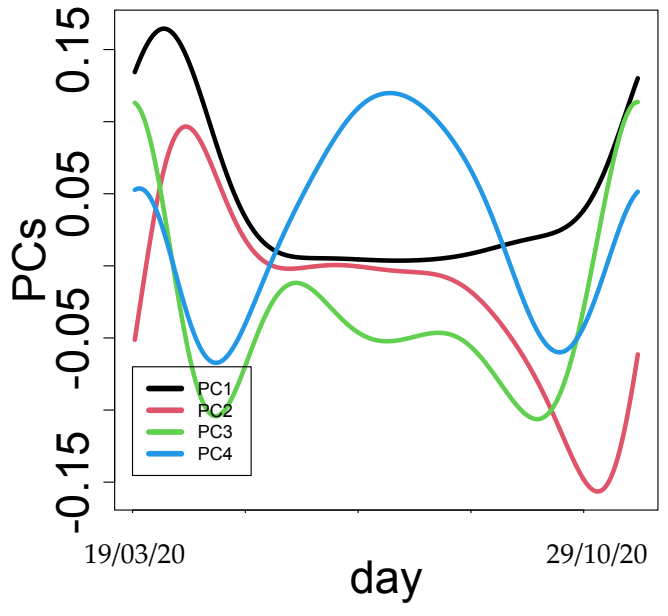

(a)

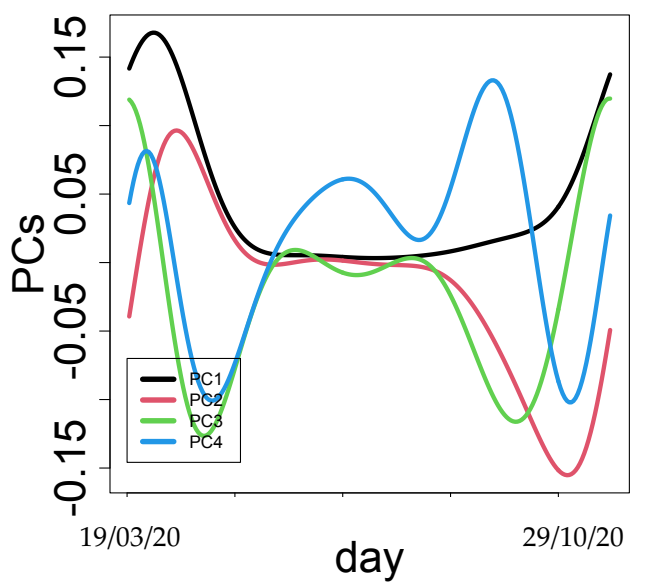

(c)

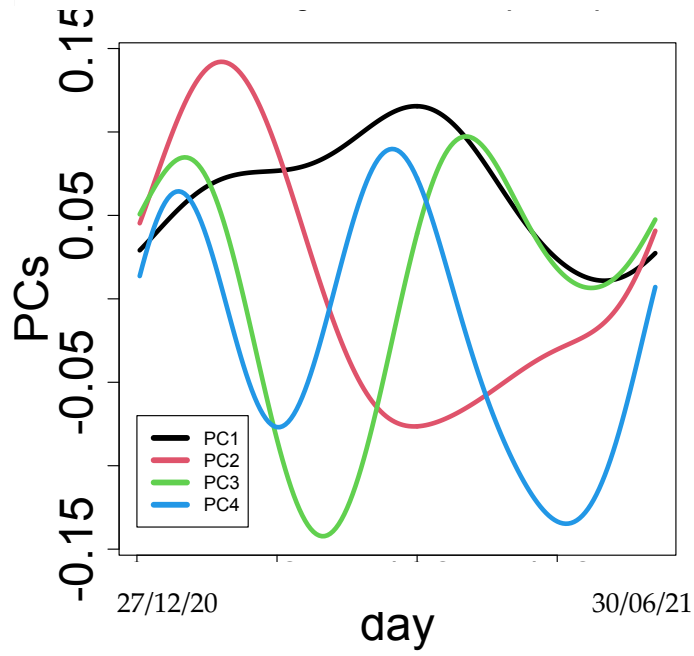

(b)

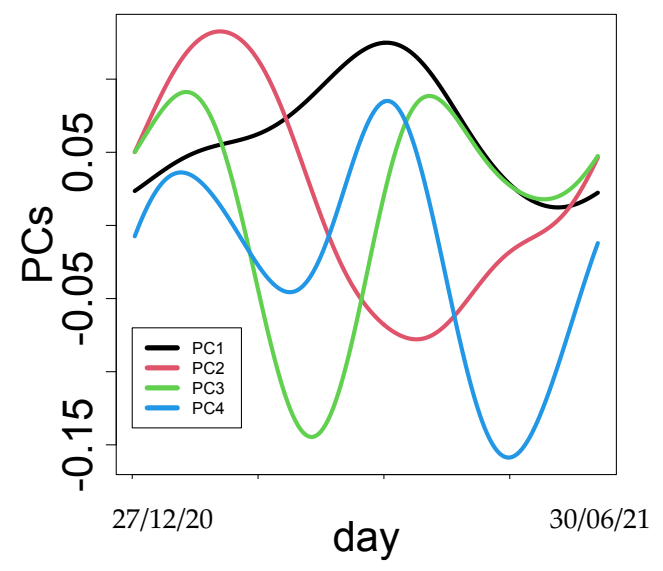

(d) 


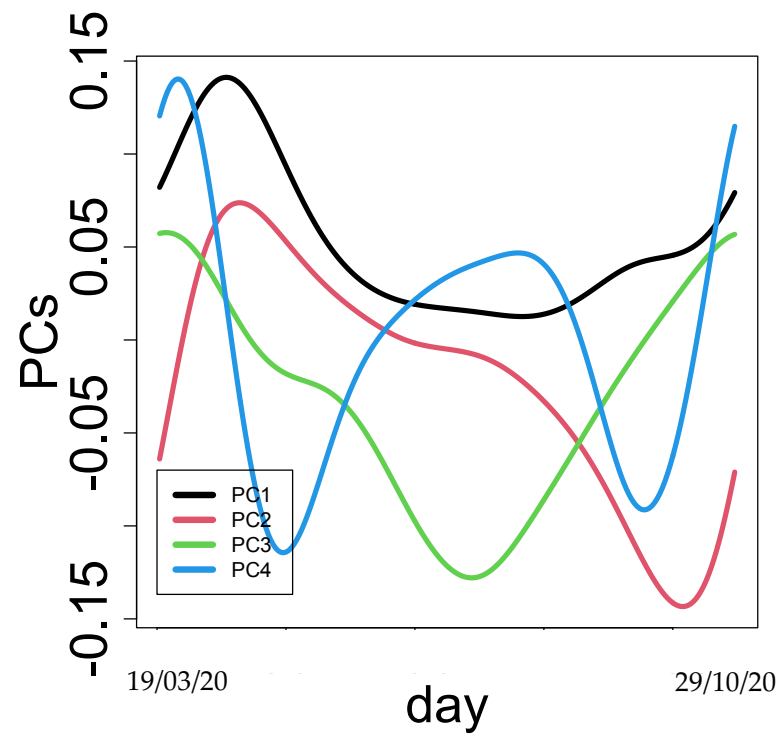

(e)

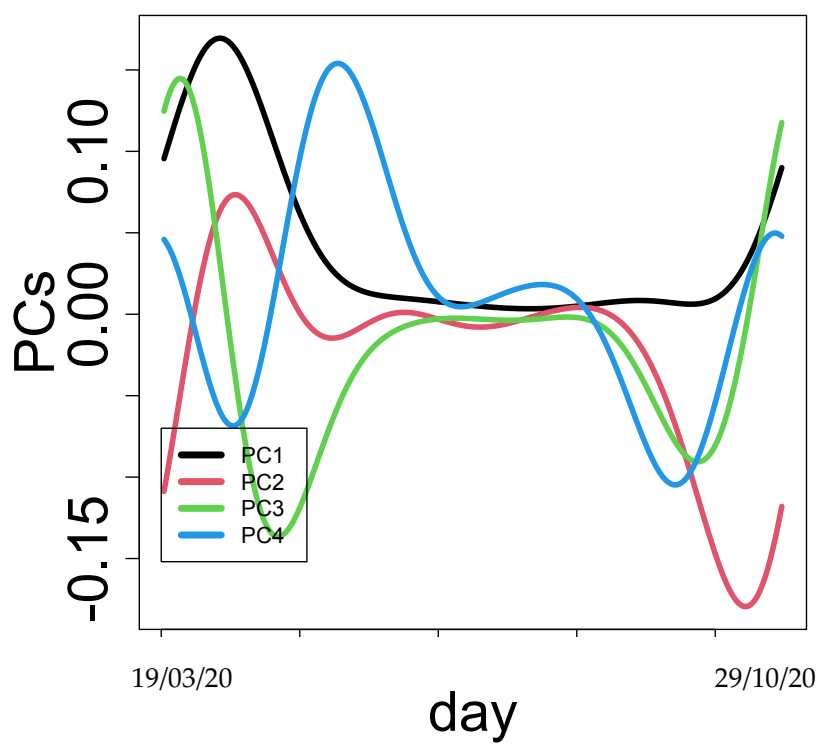

(g)

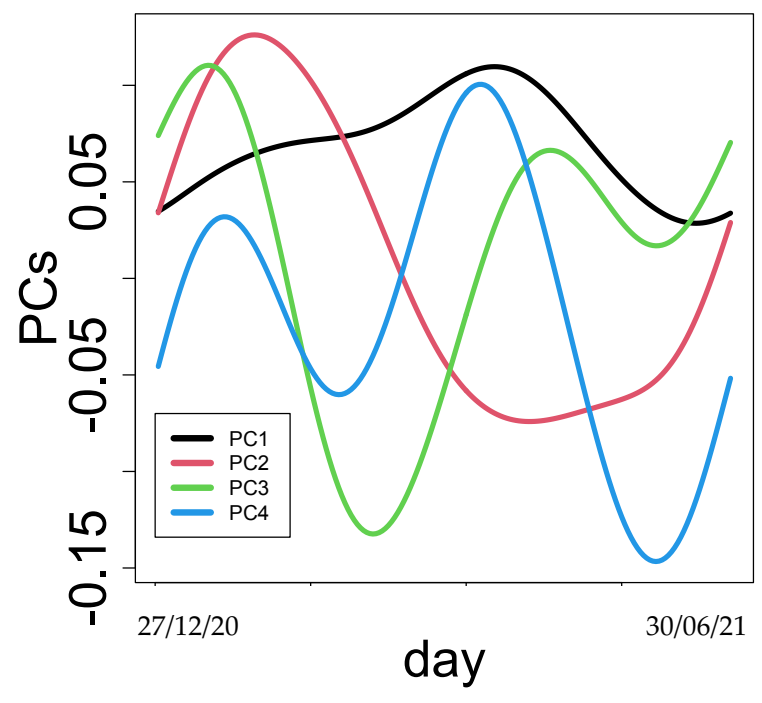

(f)

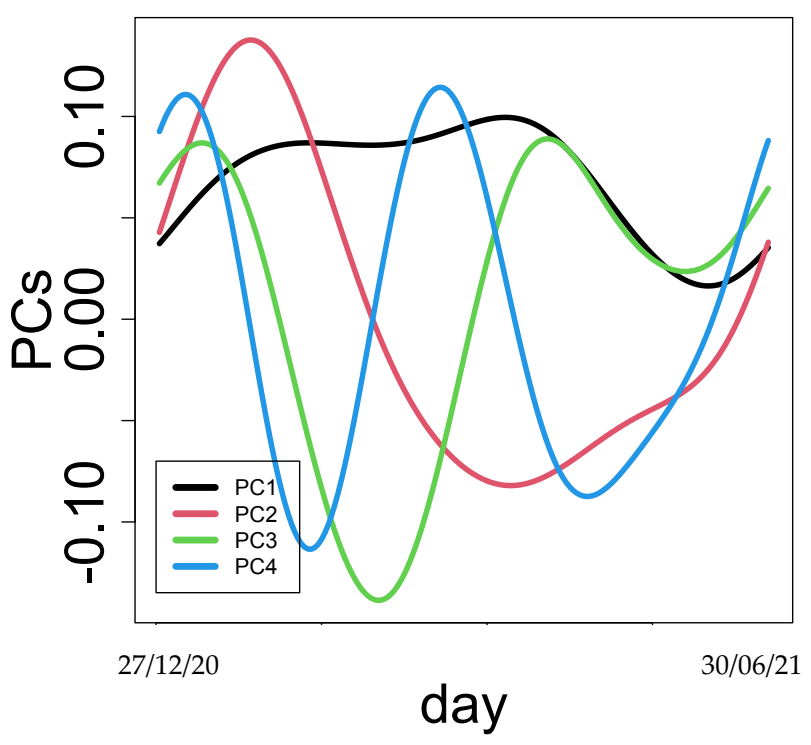

(h)

Figure 6. Functional PCs for different functional data before the start of vaccination (19/03/2020 to 29/10/2020) and when vaccination has started (27/12/2020 to 30/06/2021): (a) hospitalized cases, (b) hospitalized when vaccination has started, (c) ICU cases, (d) ICU cases when vaccination has started, (e) daily return home, (f) daily return home when vaccination has started, (g) 
Functional principal component scores and clusters

We will now focus more on the departments in which the pandemic is more prevalent and also on PC 1 and PC 2, neglecting the other PCs. In Figure 7a, the Paris department (code number 75) and Nord department (code number 59) have a positive score in PC 1 and negative score in PC 2 while the Essonne department is positive in both PCs. In Figure 7b, the Paris department and Essonne department (code number 91) are negative in both PCs while the Nord department is positive in PC 2 with the highest score and negative in PC1. In Figure 7c, Nord and Essonne departments are negative in PC 2 but positive in PC 1 while the Paris department is positive in both PCs. The Paris department and Essonne department are negative in both PCs in Figure 7d while the Nord department is positive in PC 2 and negative in PC1. In Figure 7e, Paris and Nord departments have positive scores in both PCs while the Essonne department is negative in PC2 and positive in PC 1. Nord department has the highest positive score in PC 1 for Figure $7 \mathrm{f}$ and negative for PC1, Paris department is positive in PC 2 and negative in PC while Essonne department is negative in both PCs. The Paris department has the highest positive score in PC 1 and negative in PC 2 in Figure 7g, Nord department is positive in both PCs while Essonne department is negative in PC 2 but positive in PC 1. Finally, in Figure 7h while Nord department is positive and highest in PC 2, Paris department is the lowest with negative score in PC 2. Both departments are negative in PC 1. The Essonne department is positive in PC 2 but negative in PC 1.

The above description shows that there is a difference between the vaccination period in France and the period when measures like lockdown, social distancing etc. were only used to control the spread of the virus despite the fact that it has been proven medically

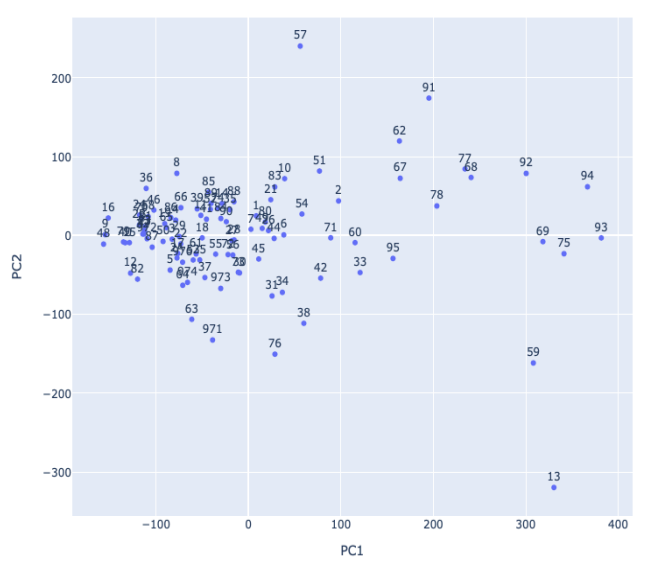

(a)

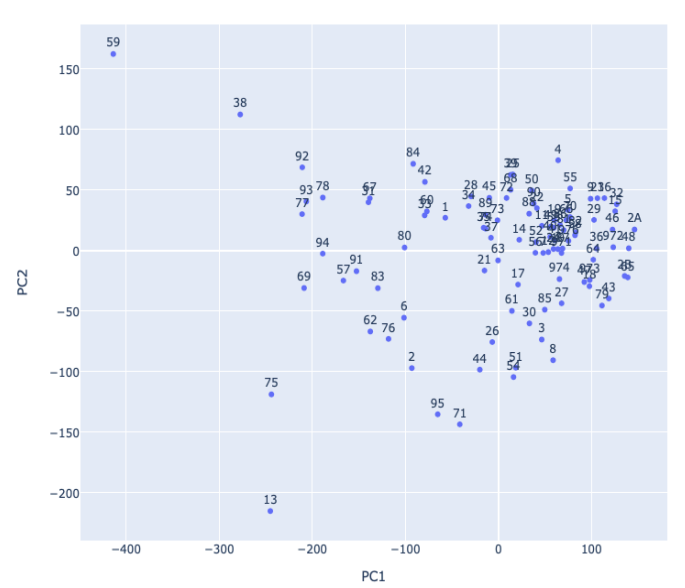

(b) 
medRxiv preprint doi: https://doi.org/10.1101/2021.09.25.21264106; this version posted September $28,2021$. The copyright holder for this preprint (which was not certified by peer review) is the author/funder, who has granted medRxiv a license to display the preprint in

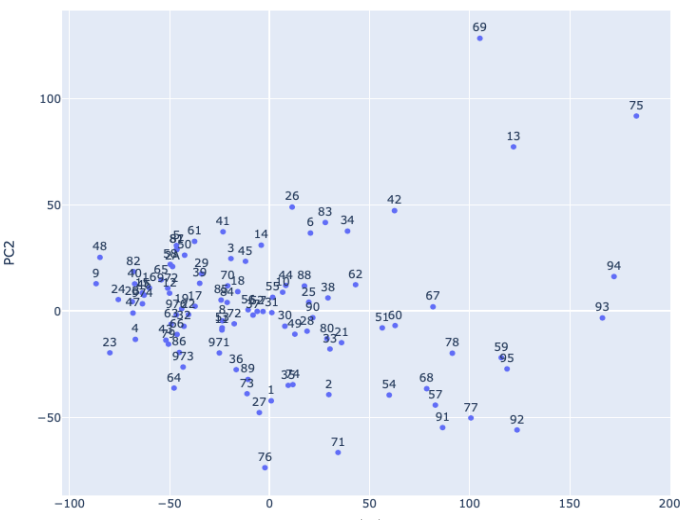

(c)

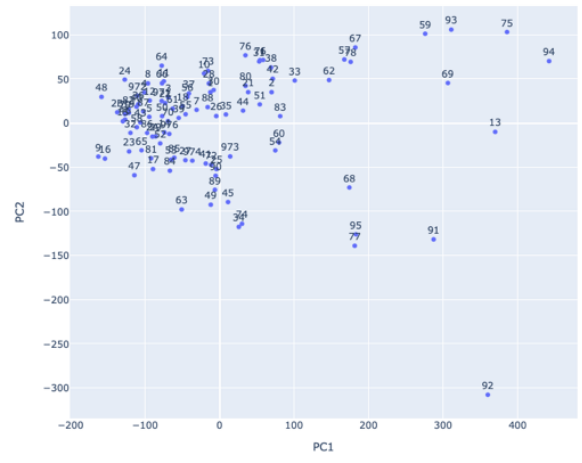

(e)

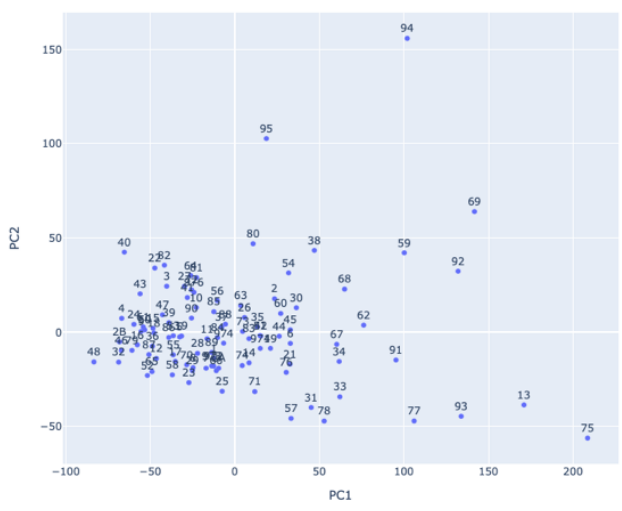

(g)

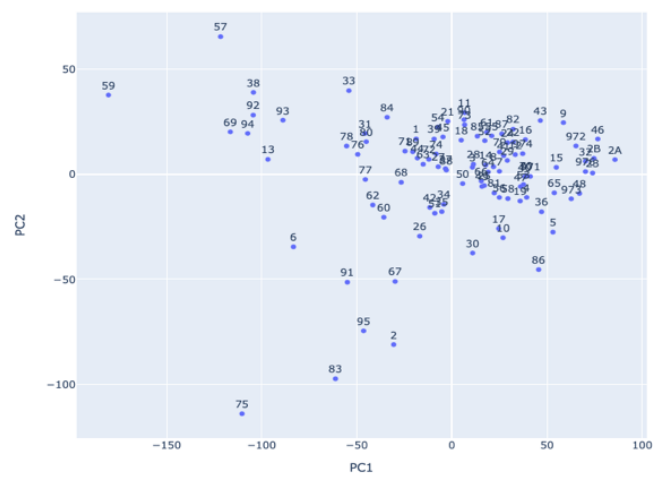

(d)

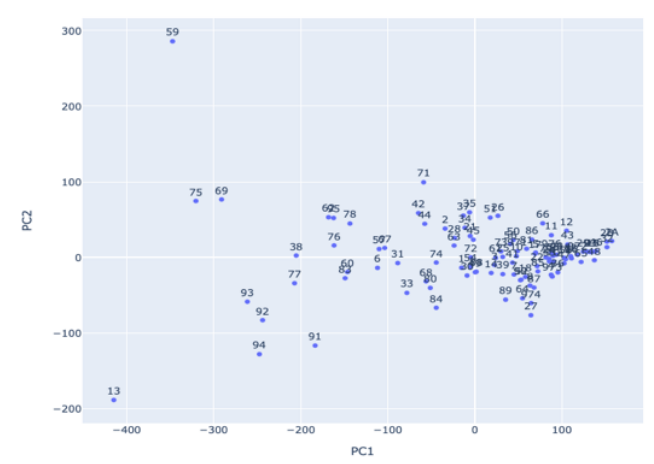

(f)

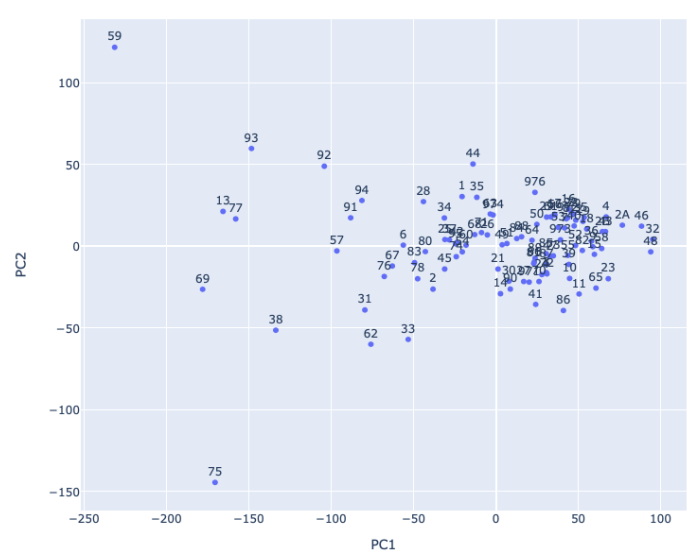

(h)

Figure 7. FPCA scores for different functional data before the start of vaccination (19/03/2020 to 29/10/2020) and when cases, (d) ICU cases when vaccination has started, (e) daily return home, (f) daily return home when vaccination has started, (g) daily deceased and (h) daily deceased when vaccination has started. Note that the numbering of points on the diagram are codes for each French department. 


\section{Canonical Correlation Analysis (CCA)}

Canonical correlation is an aspect of multivariate statistical analysis method that is used to simultaneously correlate several metric dependent variables and several metric independent variables measured on or observed with similar experimental units. PCA is often used for dimensionality reduction of a particular data set through linear combinations of the initial variables which maximizes the amount of variance explained by these linear combinations while CCA finds linear combinations within a data set with the goal of maximizing the correlation between these linear combinations [7].

where, $x_{i}=\left[\begin{array}{c}x_{i 1} \\ x_{i 2} \\ x_{i 3} \\ \cdots \\ x_{i n}\end{array}\right], y_{i}=\left[\begin{array}{c}y_{j 1} \\ y_{j 2} \\ y_{j 3} \\ \cdots \\ y_{j q}\end{array}\right]$.

The purpose of canonical correlation analysis is to find coefficient vectors $\boldsymbol{a}_{\mathbf{1}}=\left(a_{11}, a_{21}, \ldots, a_{p 1}\right)^{T}$ and $\boldsymbol{b}_{\mathbf{1}}=\left(b_{11}, b_{21}, \ldots\right.$, $\left.b_{q 1}\right)^{T}$ to maximize the correlation $\beta=\operatorname{corr}\left(X \boldsymbol{a}_{1}, Y \boldsymbol{b}_{1}\right)$ while $U_{1}=X \boldsymbol{a}_{1}$ and $V_{1}=Y \boldsymbol{b}_{1}$, linear combinations of $\mathrm{X}$ and $\mathrm{Y}$ components respectively, constitute the first pair of canonical covariates. Then, the second pair of canonical variates can be found in the same way subject to the constraint that they are uncorrelated with the first pair of variables. By repeating this procedure, $r=\min \{p, q\}$ pairs of canonical variates can be found and we will finally get two matrices $\mathrm{A}=\left[\boldsymbol{a}_{1}, \boldsymbol{a}_{2}, \boldsymbol{a}_{3}, \ldots \boldsymbol{a}_{r}\right]$ and $\mathrm{B}=$ $\left[\boldsymbol{b}_{1}, \boldsymbol{b}_{2}, \boldsymbol{b}_{3}, \ldots \boldsymbol{b}_{\boldsymbol{r}}\right]$ to transfer $\mathrm{X}$ and $\mathrm{Y}$ to canonical variates $\mathrm{U}$ and $\mathrm{V}$ following the below expression:

$$
U_{n \times r}=X_{n \times p} A_{p \times r}, \quad V_{n \times r}=Y_{n \times p} B_{p \times r} .
$$

If $\mathrm{X}$ and $\mathrm{Y}$ are both centered, we can concatenate them and calculate the covariance matrix given as:

$C=\operatorname{Cov}([X Y])=\frac{1}{n-1}[X Y]^{T}[X Y]=\left[\begin{array}{ll}C_{x x} & C_{x y} \\ C_{y x} & C_{y y}\end{array}\right]$

where $C_{x x}$ and $C_{y y}$ are within-set covariance matrices, and $C_{x y}=\left[C_{y x}\right]^{T}$ are between-set covariance matrices. The first canonical variates $\boldsymbol{a}_{\mathbf{1}}$ and $\boldsymbol{b}_{\mathbf{1}}$ maximize the equation below:

$$
\beta_{1}=\frac{\boldsymbol{a}_{\mathbf{1}}{ }^{T} C_{x y} \boldsymbol{b}_{\mathbf{1}}}{\sqrt{\boldsymbol{a}_{\mathbf{1}}{ }^{T} C_{x x} \boldsymbol{a}_{\mathbf{1}}} \sqrt{\boldsymbol{b}_{\mathbf{1}}{ }^{T} C_{y y} \boldsymbol{b}_{\mathbf{1}}}},
$$

The subsequent pairs of canonical variates $\boldsymbol{a}_{\boldsymbol{i}}$ and $\boldsymbol{b}_{\boldsymbol{i}}(\mathrm{i} \geq 2)$ maximize:

$$
\beta_{i}=\frac{\boldsymbol{a}_{\boldsymbol{i}}{ }^{T} C_{x y} \boldsymbol{b}_{\boldsymbol{i}}}{\sqrt{\boldsymbol{a}_{\boldsymbol{i}}{ }^{T} C_{x x} \boldsymbol{a}_{\boldsymbol{i}}} \sqrt{\boldsymbol{b}_{\boldsymbol{i}}{ }^{T} C_{y y} \boldsymbol{b}_{i}}}
$$

subject to the constraint:

$$
\begin{array}{r}
\boldsymbol{a}_{\boldsymbol{i}}{ }^{T} C_{x x} \boldsymbol{a}_{\boldsymbol{j}}=0 \forall j<i, \\
\boldsymbol{b}_{\boldsymbol{i}}{ }^{T} C_{y y} \boldsymbol{b}_{j}=0 \forall j<i .
\end{array}
$$

The analysis was performed in $\mathrm{R}$ using a package $C C A$. We present the visualization results on Figures 8 and 9 and also present the correlation scores in tabular form (see Table 3). We used the variables as presented in Table 3. X are the variables in the first column of Table 3 i.e., total number of hospitalization, daily return home, deceased and ICU cases for all departments and Y variables are the response variables described earlier as presented in the first row of Table 3. 
medRxiv preprint doi: https://doi.org/10.1101/2021.09.25.21264106; this version posted September 28, 2021. The copyright holder for this preprint (which was not certified by peer review) is the author/funder, who has granted medRxiv a license to display the preprint in perpetuity.

All rights reserved. No reuse allowed without permission.

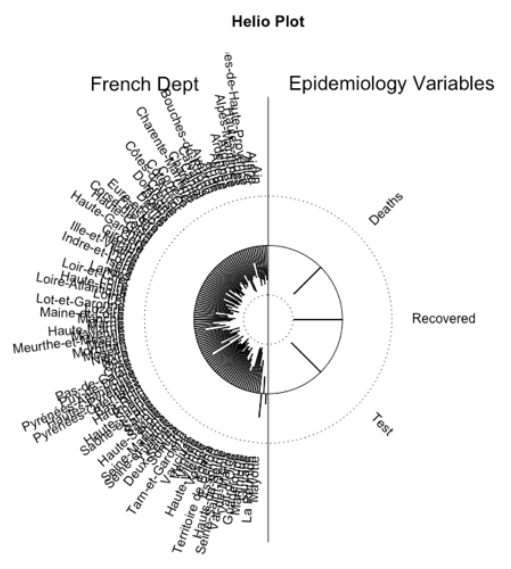

(a)

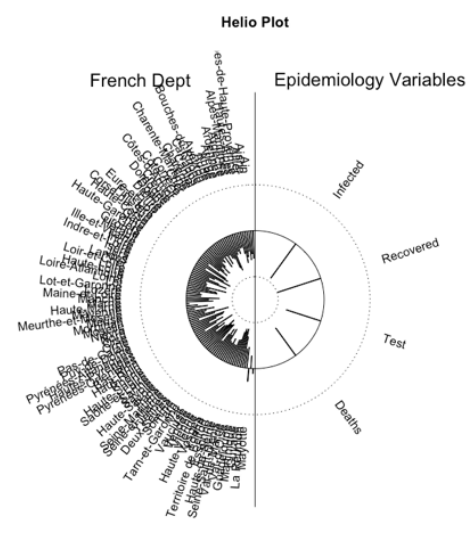

(c)

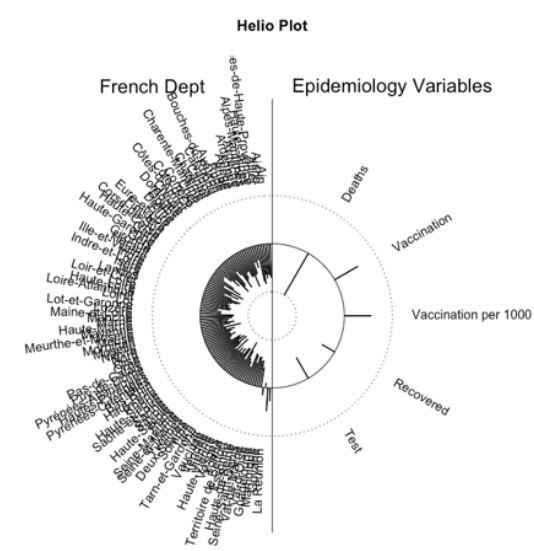

(b)

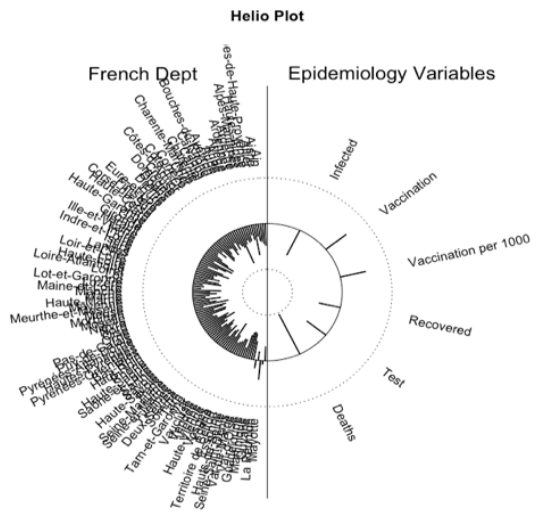

(d)

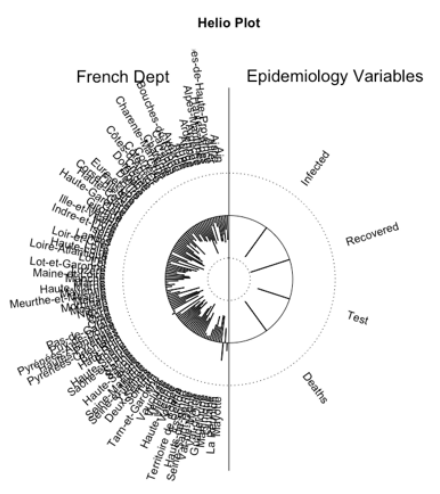

(e)

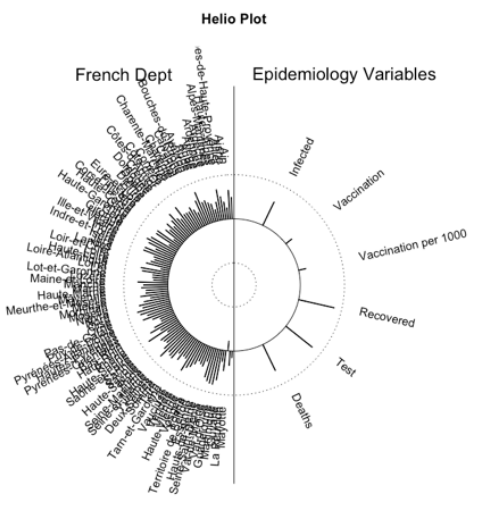

(f) 


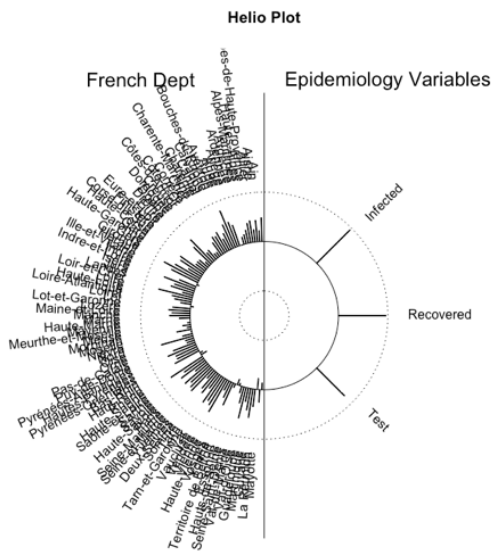

(g)

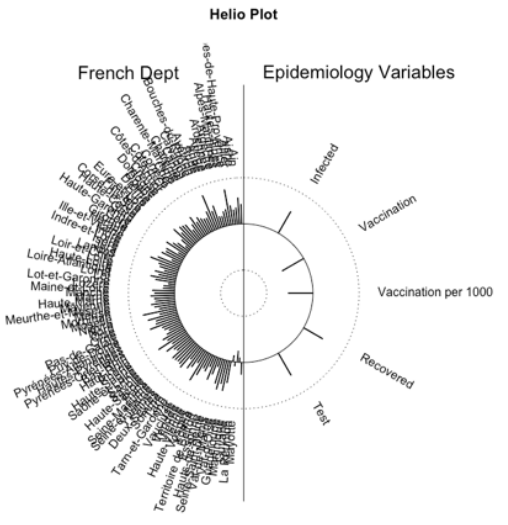

(h)

Figure 8. Helio plot for the correlation of French departments for (a) hospitalized cases, (b) hospitalized when vaccination has started, (c) ICU cases, (d) ICU cases when vaccination has started, (e) daily return home, (f) daily return home when vaccination has started, (g) daily deceased and (h) daily deceased when vaccination has started.

292

293

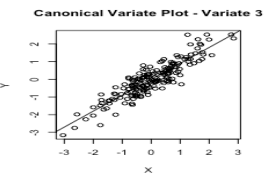

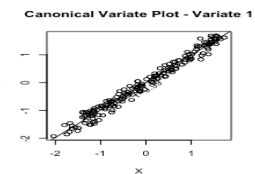

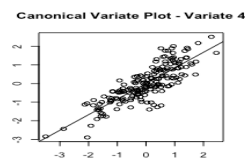

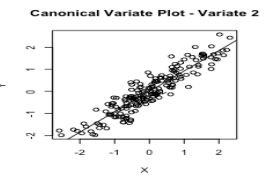

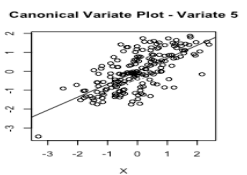

(a)

(b) 
medRxiv preprint doi: https://doi.org/10.1101/2021.09.25.21264106; this version posted September 28, 2021. The copyright holder for this
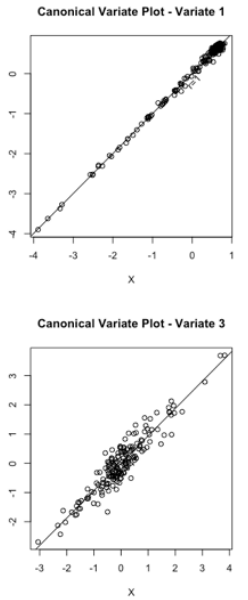

(c)
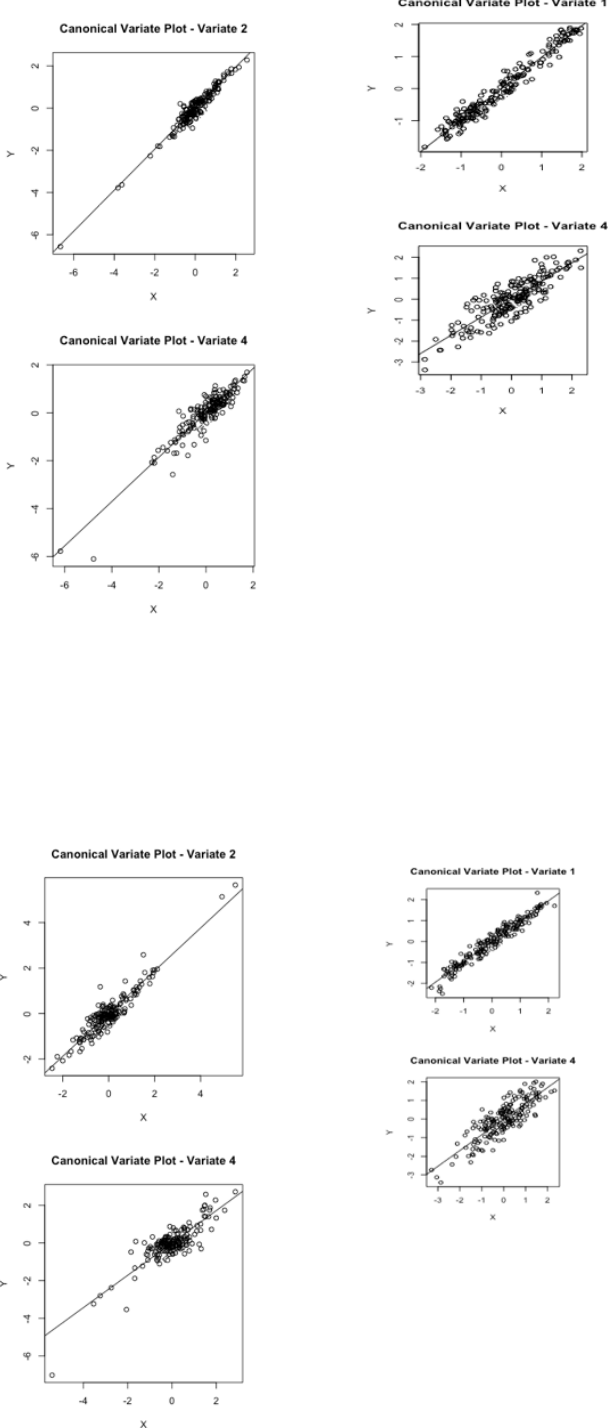

(e)
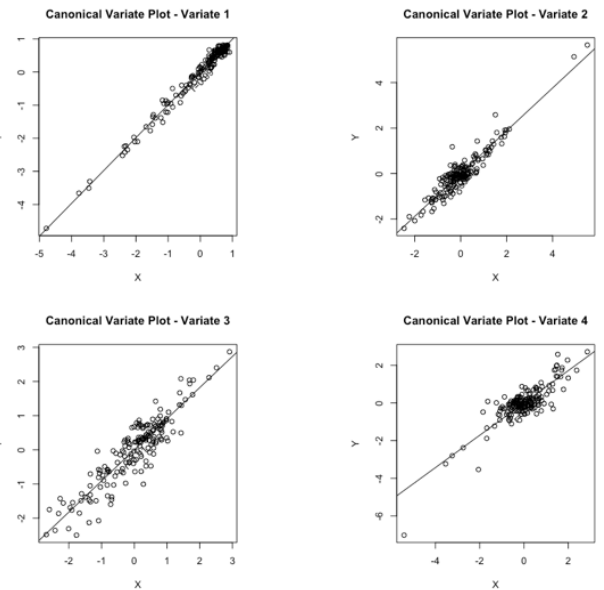
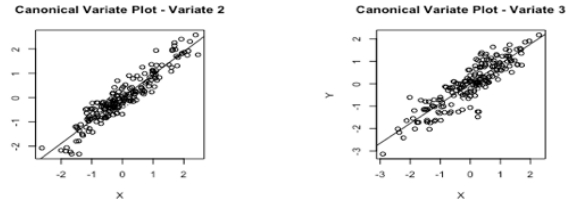

(d)
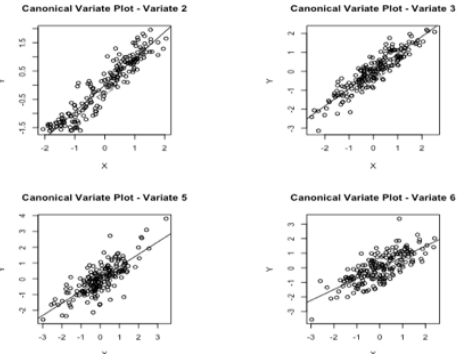

Canonical Variate Plot - Variate 1

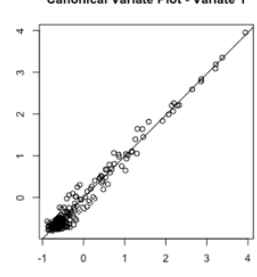

Canonical Variate Plot - Variate 3

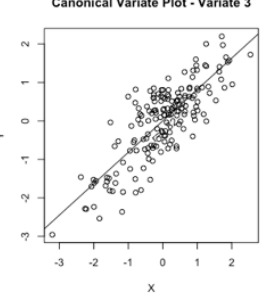

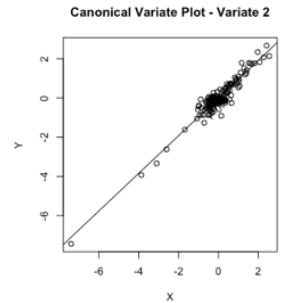

(g) (f)
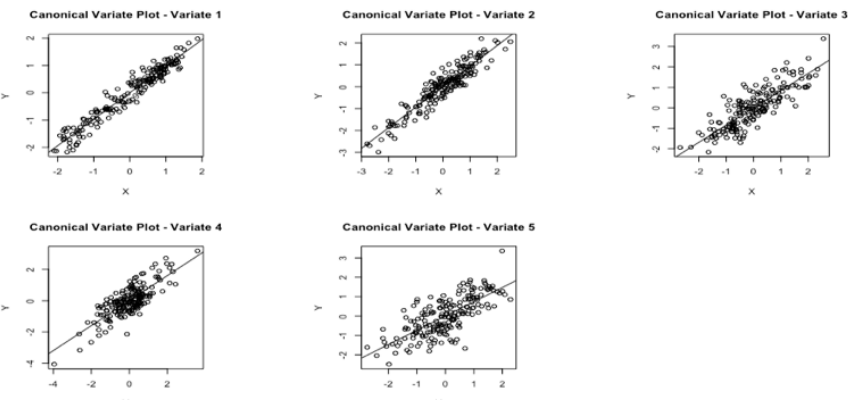

(h) 
Figure 9. Canonical correlation visualization of (a) hospitalized cases, (b) hospitalized when vaccination has started, (c) ICU

The results presented in Figure 9 show the linear relations in the scatter plot as most of the variables show 95\% significance level and from Table 3 there is high correlations between the variables considered. In Figure 8, the helio plot presents the relationships between the different departments in France.

Figure 9a shows hospitalized cases with $\mathrm{p}$-value $<0.05$ for all canonical variate, Figure $9 \mathrm{~b}$ shows hospitalized when vaccination

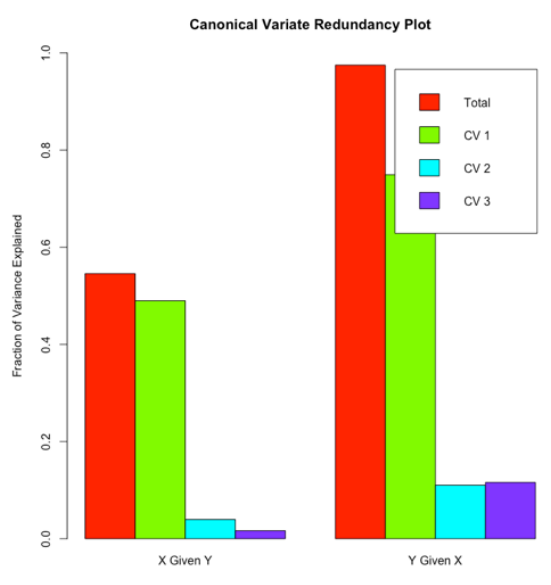

(a)

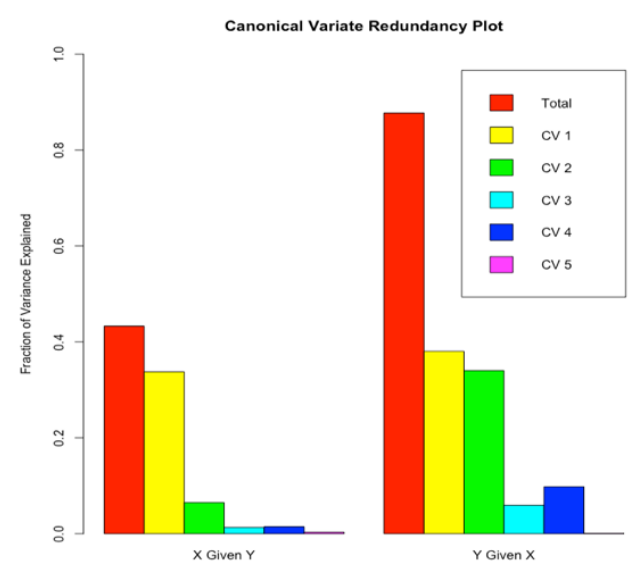

(b) 
medRxiv preprint doi: https://doi.org/10.1101/2021.09.25.21264106; this version posted September 28, 2021. The copyright holder for this preprint (which was not certified by peer review) is the author/funder, who has granted medRxiv a license to display the preprint in

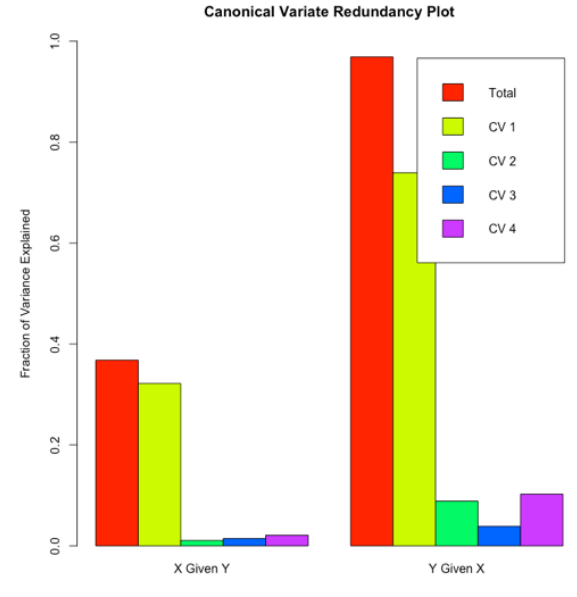

(c)

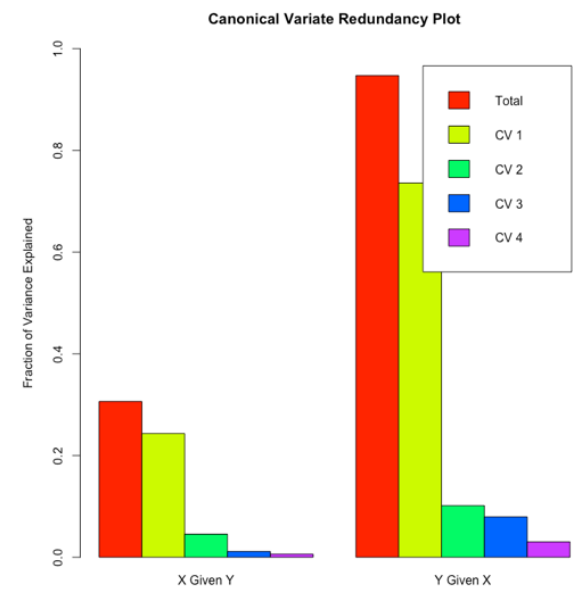

(e)

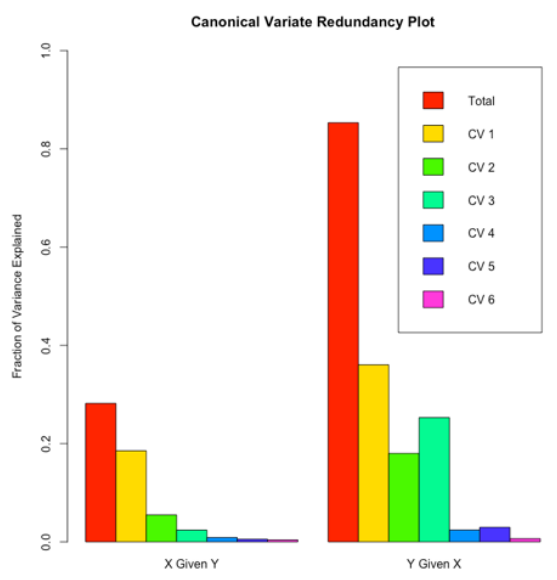

(d)

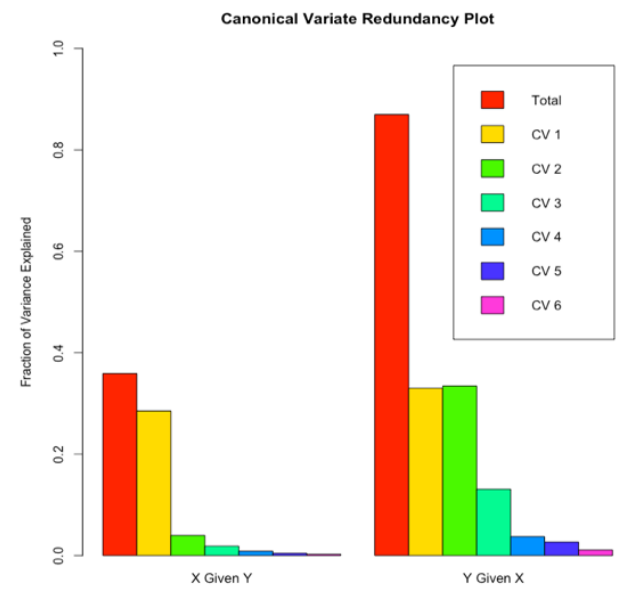

(f) 


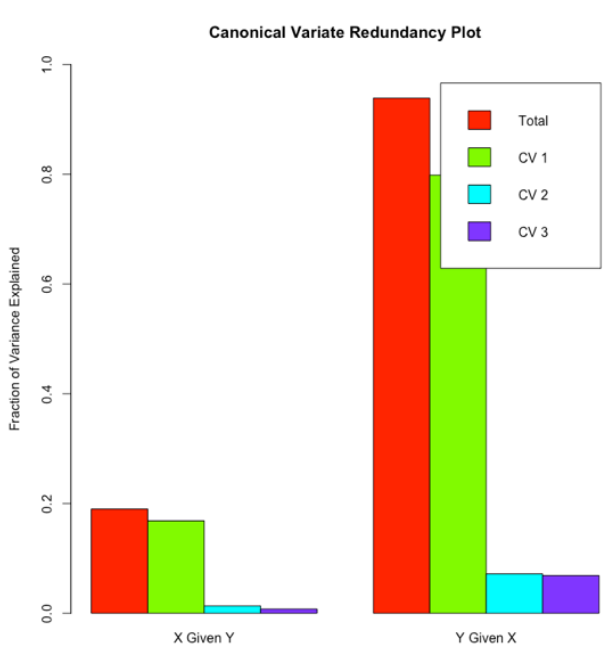

(g)

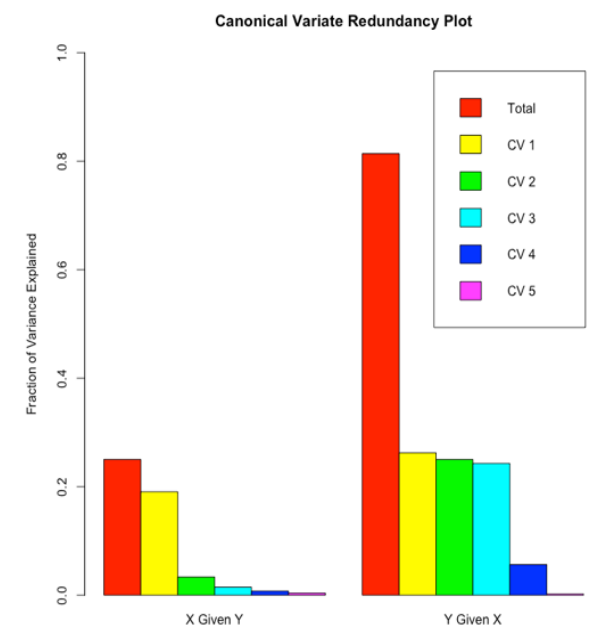

(h)

Figure 10. Canonical variate redundancy plot for (a) hospitalized cases, (b) hospitalized when vaccination has started, (c) ICU cases, (d) ICU cases when vaccination has started, (e) daily return home, (f) daily return home when vaccination has started, (g) daily deceased and (h) daily deceased when vaccination has started.

Table 3. Canonical correlation scores

\begin{tabular}{|c|c|c|c|c|c|}
\hline \multicolumn{6}{|c|}{ Before vaccination started } \\
\hline & Hospitalized & ICU & Daily return home & Daily deceased & Hospitalized \\
\hline Deaths & 0.996 & 0.926 & 0.859 & - & 0.989 \\
\hline Recovered & 0.970 & 0.973 & 0.941 & 0.961 & 0.838 \\
\hline Test & 0.950 & 0.937 & 0.911 & 0.816 & 0.685 \\
\hline Vaccination & - & - & - & - & 0.924 \\
\hline Infected & - & 0.998 & 0.992 & 0.987 & - \\
\hline Vaccination/1000 & - & - & - & - & 0.901 \\
\hline
\end{tabular}
After vaccination has started

\begin{tabular}{|c|c|c|}
\hline ICU & Daily return home & Daily deceased \\
\hline 0.689 & 0.745 & - \\
\hline 0.865 & 0.846 & 0.797 \\
\hline 0.750 & 0.776 & 0.736 \\
\hline 0.942 & 0.939 & 0.936 \\
\hline 0.980 & 0.971 & 0.970 \\
\hline 0.885 & 0.917 & 0.841 \\
\hline
\end{tabular}

\section{Clustering method}

The clustering of functional data is one method that statisticians are always interested in and in this Section we used the K-means and Fuzzy K-means techniques whose algorithm is already in Python skfd.ml.clustering and FuzzyCMeans. These methods will enable us to visualize how various departments are clustered based on our functional data and to give it the best interpretation based on their geographical location. The basic function used for the K-means clustering is a B-spline and results of our clusters are presented below. We present the result in the cluster form and also on the map of France with indication of the membership to the 3 clusters $(0,1$ or 2$)$ to get a clearer view of the result. We only presented the result for two cases (daily hospitalized and daily deceased) for the period before vaccination begins in France and two cases (daily return and ICU cases) for the period when vaccination has started in France. In Figures 11 a to $11 \mathrm{~d}$ we present the clusters $(0,1$ or 2$)$ that each French departments belongs to. The result clustered French departments outside France to the same clusters which of course are not binded with mitigation measures and rules used in departments within France. Also, departments with close proximity with Paris are in the same cluster which is the same with departments having the same trend of the pandemic prevalence as presented in Figures 11a to 11d. 


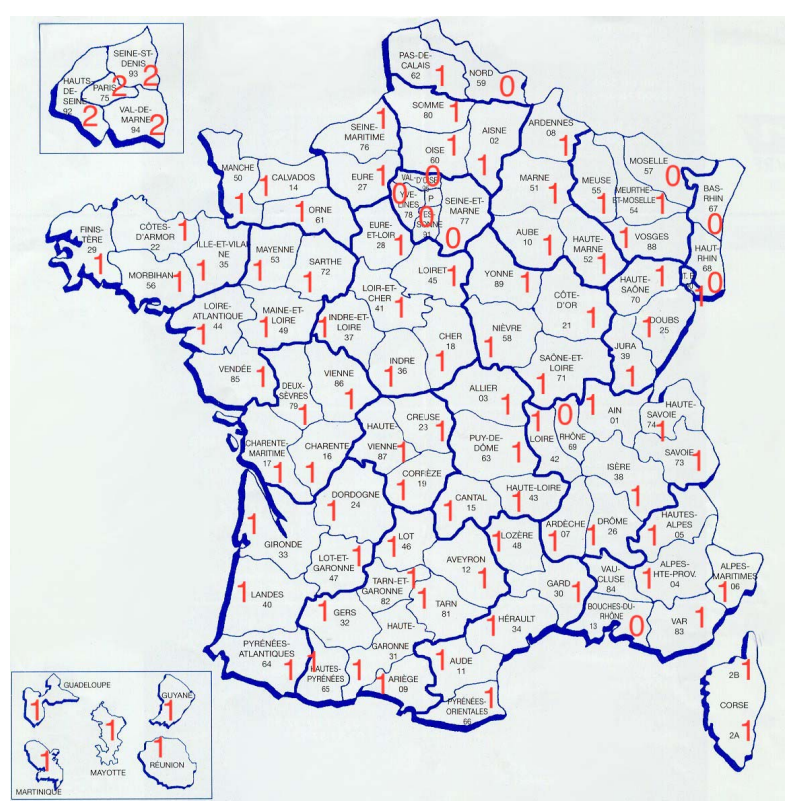

(a)

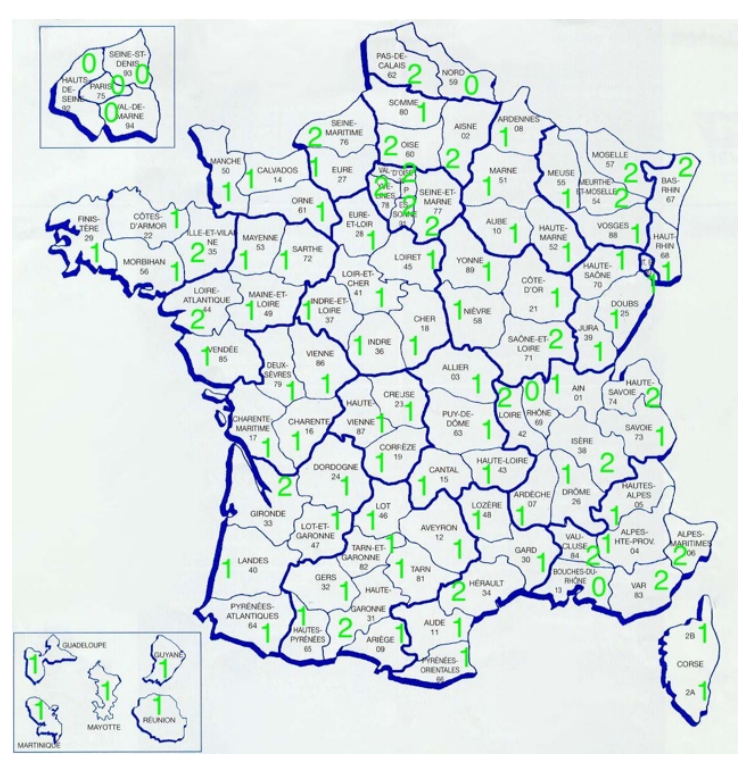

(c)

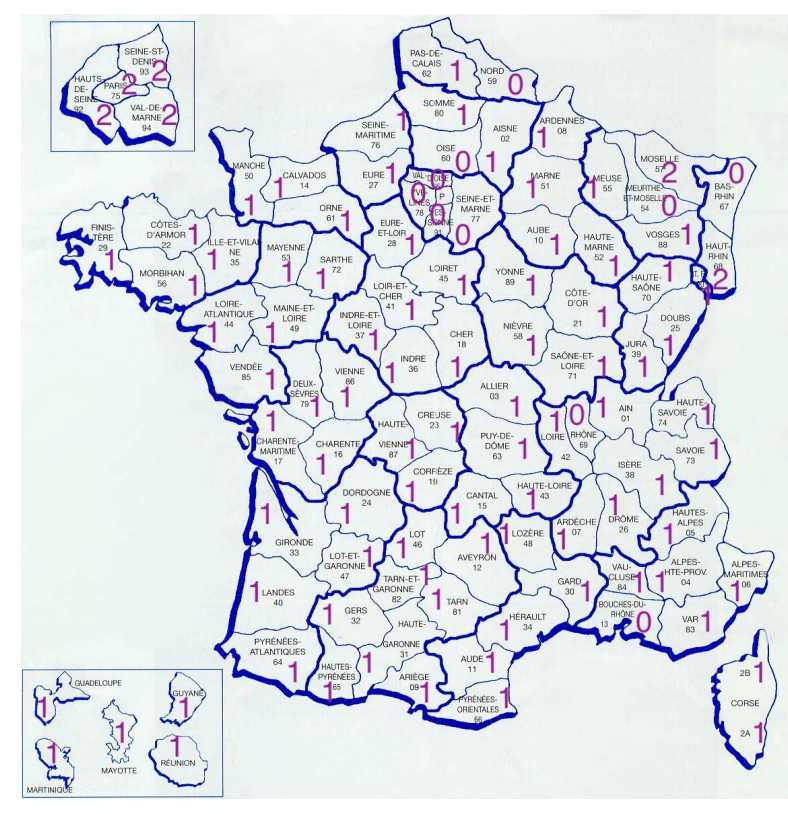

(b)

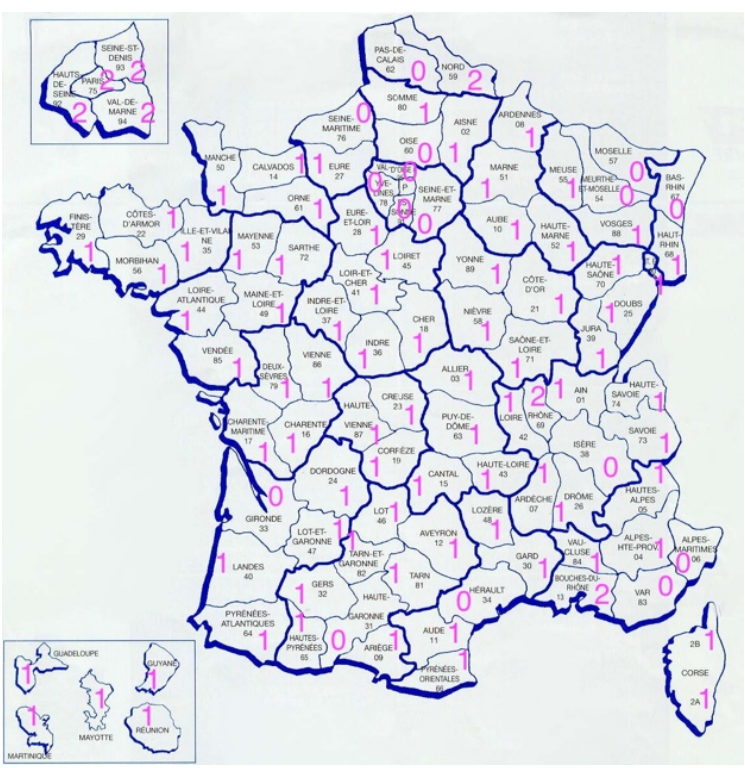

(d) 


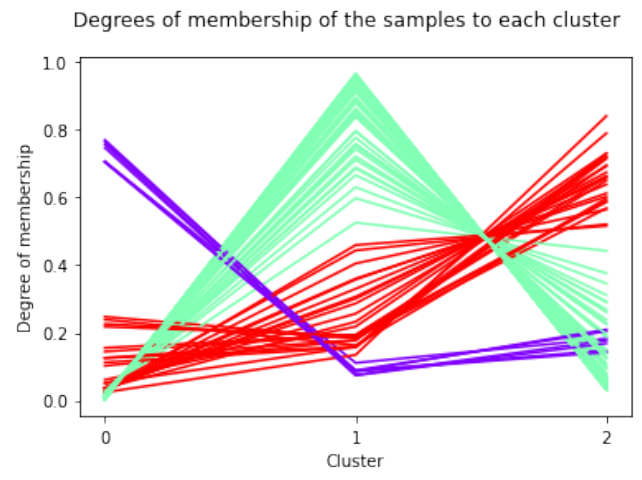

(e)

Degrees of membership of the samples to each cluster

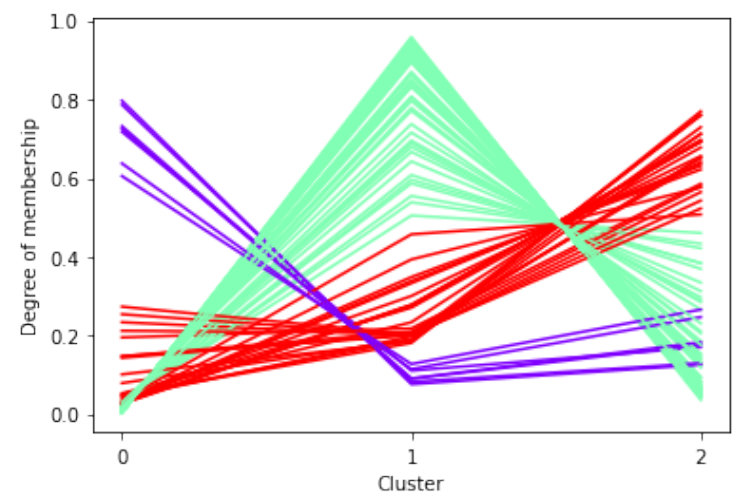

(g)

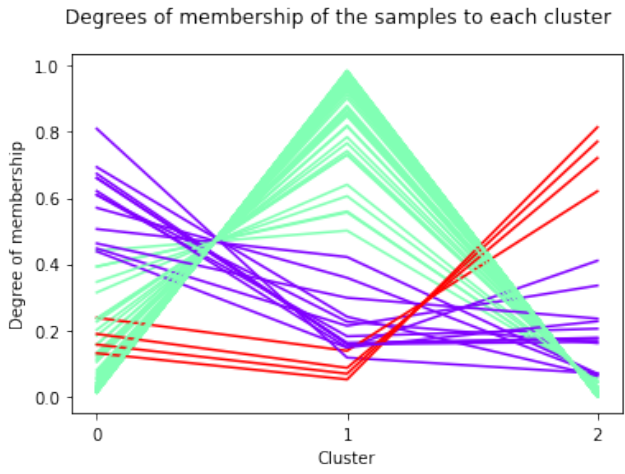

(f)

Degrees of membership of the samples to each cluster

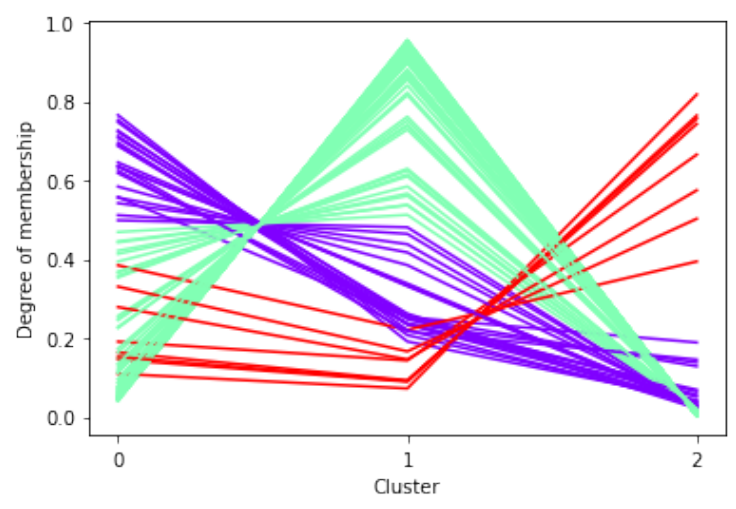

(h)
Figure 11. Clustering of all departments in France using K-means ((a) hospitalized, (b) daily deceased, (c) daily return home when vaccination has started and (d) ICU cases when vaccination has started) and Fuzzy K-means ((e) clusters for hospitalized, (f) clusters for daily deceased, (g) clusters for daily return home when vaccination has started and (h) clusters for ICU when vaccination has started).

\section{Prediction}

$$
\mathrm{Y}=\langle\theta, \mathrm{X}\rangle+\epsilon
$$

where $\theta$ is the unknown function of the model, $\mathrm{X}$ is a functional covariate belonging to some functional space $\mathbb{H}$ which is endowed with an inner product $\langle.,\rangle,. \mathrm{Y}$ is the response variable and $\epsilon$ is the random error term. Usually, $\mathbb{H}$ is the space $L^{2}([a, b])$ of square integrable functions on some real compact interval $[a, b]$ and

$$
<f, g>=\int_{a}^{b} f(t) g(t) d t,
$$

Then, we consider $\mathrm{C}=[0,1]$, so the equation (12) can be written as:

where $\theta$ is a square integrable function which is is defined on $\mathrm{C}$ and $\epsilon$ is a random variable such that $\mathbb{E}(\epsilon)=0$ and $\mathbb{E}(X(t) \epsilon)=$ 0 . The equation 14 can be rewritten as: 
where $\Psi$ represents the integral.

We treated the functional data (hospitalization) as a curve whose prediction is linked to a scalar (number of deaths and tests) response variable. The data considered are data before vaccination started in France and we trained $80 \%$ of the data and $20 \%$ was tested. The visualization of the results is presented in the Figure 12 and the tabular form of the numerical results can be found in Table 4 . The prediction affirms the fact that the relaxation in the mitigation measures observed during the period we predicted increases the number of deaths and tests in France which is why the predicted results are a bit higher than the observed values as seen in Figure 12 and Table 4.

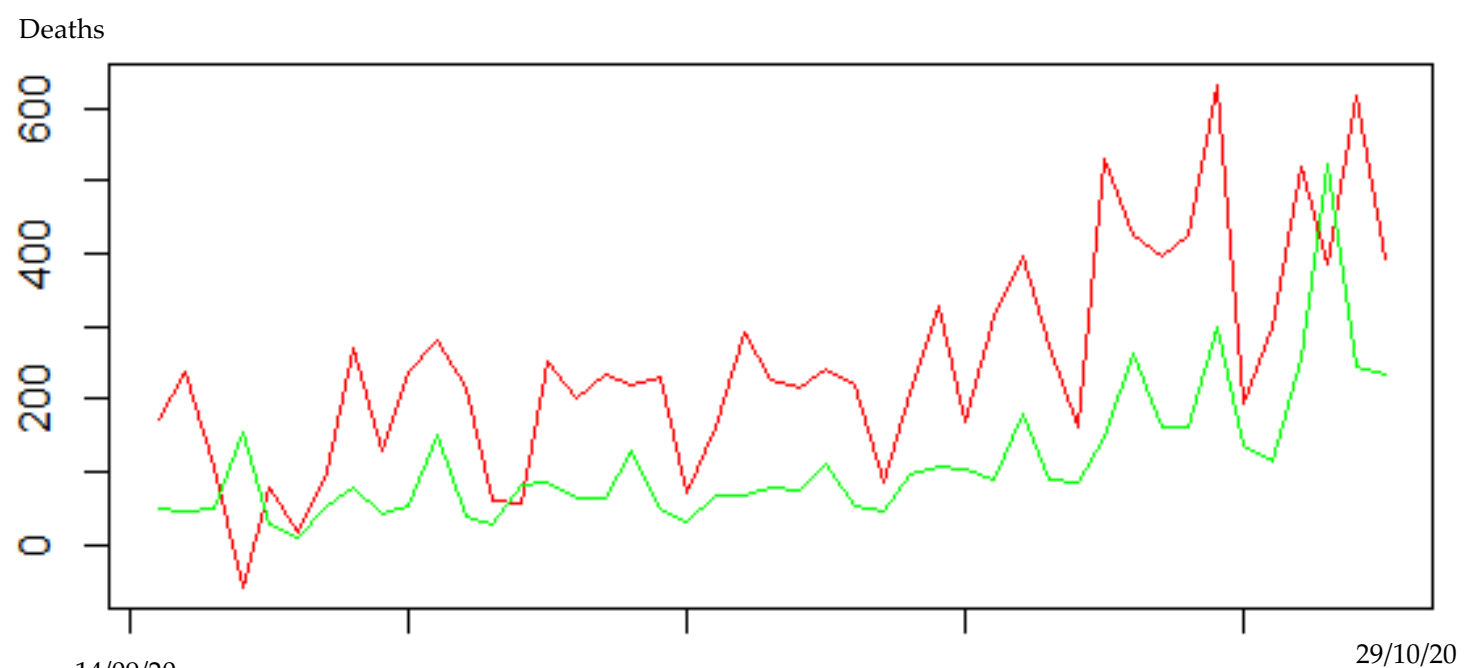

Days

- predicted - actual

(a) 


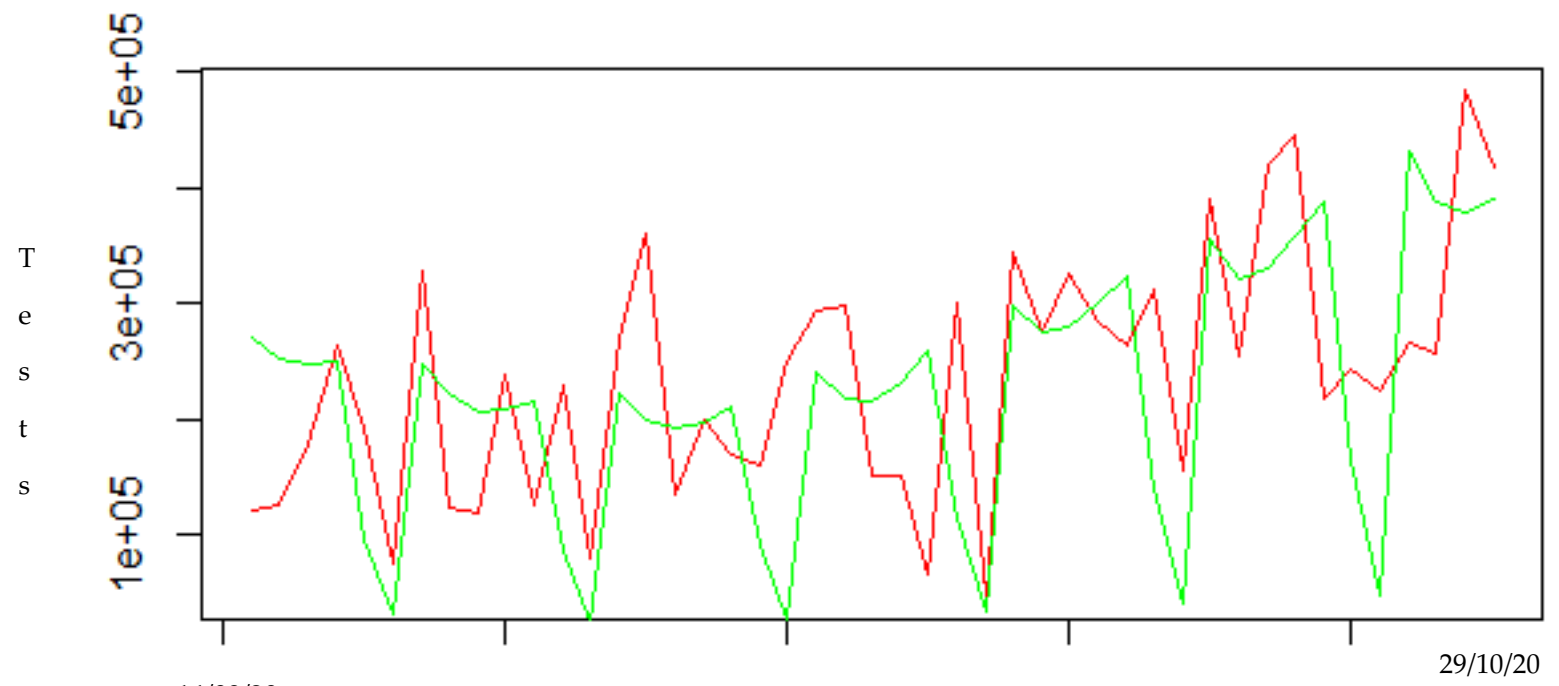

$14 / 09 / 20$

\section{Days \\ - predicted -actual}

(b)

Figure 12. (a) Functional linear regression model prediction for number of deaths in France as response variable before vaccination begins and (b) Functional linear regression model prediction for number of tests in France as response variable before vaccination begins.

Table 4. Comparison of the predicted and actual values

\begin{tabular}{|c|c|}
\hline & Deaths \\
\hline Day & Actual \\
\hline 1 & 49 \\
\hline 2 & 46 \\
\hline 3 & 50 \\
\hline 4 & 153 \\
\hline 5 & 26 \\
\hline 6 & 11 \\
\hline 7 & 53 \\
\hline 8 & 78 \\
\hline 9 & 43 \\
\hline 10 & 52 \\
\hline 11 & 150 \\
\hline 12 & 39 \\
\hline 13 & 27 \\
\hline
\end{tabular}

\begin{tabular}{|c|}
\hline Predicted \\
\hline 86 \\
\hline 136 \\
\hline 116 \\
\hline 82 \\
\hline 39 \\
\hline 97 \\
\hline 136 \\
\hline 124 \\
\hline 171 \\
\hline 175 \\
\hline 126 \\
\hline 42 \\
\hline \hline
\end{tabular}

\begin{tabular}{|c|}
\hline Actual \\
\hline 269886 \\
\hline 251301 \\
\hline 248354 \\
\hline 248910 \\
\hline 96177 \\
\hline 30345 \\
\hline 247760 \\
\hline 222942 \\
\hline 206626 \\
\hline 207651 \\
\hline 214336 \\
\hline 86361 \\
\hline 23804 \\
\hline \hline
\end{tabular}
Tests

\begin{tabular}{|c|}
\hline Predicted \\
\hline 120499 \\
\hline 126261 \\
\hline 178764 \\
\hline 264431 \\
\hline 192823 \\
\hline 75319 \\
\hline 328075 \\
\hline 124271 \\
\hline 118126 \\
\hline 237759 \\
\hline 124387 \\
\hline 229623 \\
\hline 78612 \\
\hline \hline
\end{tabular}




\begin{tabular}{|c|c|}
\hline 14 & 81 \\
\hline 15 & 85 \\
\hline 16 & 63 \\
\hline 17 & 63 \\
\hline 18 & 130 \\
\hline 19 & 49 \\
\hline 20 & 32 \\
\hline 21 & 69 \\
\hline 22 & 66 \\
\hline 23 & 80 \\
\hline 24 & 76 \\
\hline 25 & 109 \\
\hline 26 & 54 \\
\hline 27 & 46 \\
\hline 28 & 95 \\
\hline 29 & 108 \\
\hline 30 & 104 \\
\hline 31 & 88 \\
\hline 32 & 178 \\
\hline 33 & 89 \\
\hline 34 & 85 \\
\hline 35 & 146 \\
\hline 36 & 262 \\
\hline 37 & 163 \\
\hline 38 & 162 \\
\hline 39 & 298 \\
\hline 40 & 137 \\
\hline 41 & 116 \\
\hline 42 & 257 \\
\hline 43 & 523 \\
\hline 44 & 244 \\
\hline 45 & 235 \\
\hline
\end{tabular}

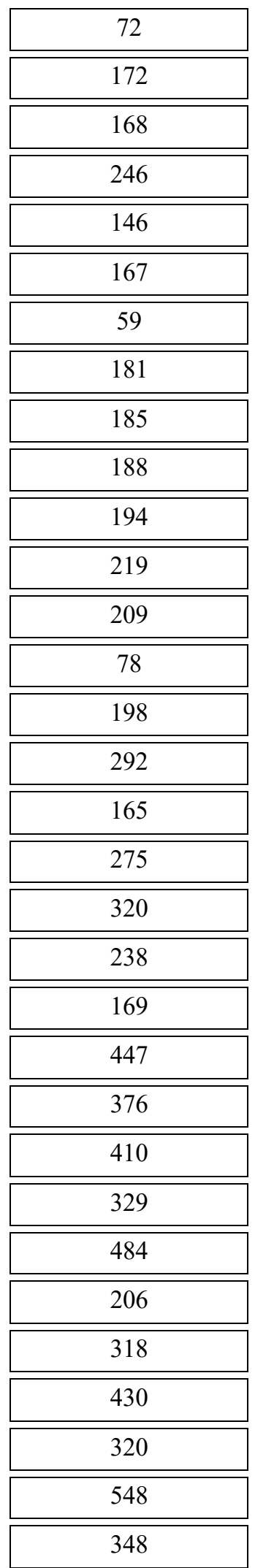

\begin{tabular}{|c|}
\hline 223293 \\
\hline 199948 \\
\hline 191917 \\
\hline 196259 \\
\hline 210495 \\
\hline 90639 \\
\hline 25699 \\
\hline 240612 \\
\hline 217585 \\
\hline 214258 \\
\hline 231306 \\
\hline 259073 \\
\hline 114369 \\
\hline 32368 \\
\hline 299121 \\
\hline 276013 \\
\hline 279376 \\
\hline 301465 \\
\hline 322468 \\
\hline 140298 \\
\hline 40313 \\
\hline 355160 \\
\hline 321373 \\
\hline 330328 \\
\hline 357368 \\
\hline 388884 \\
\hline 165764 \\
\hline 47485 \\
\hline 430644 \\
\hline 387569 \\
\hline 379590 \\
\hline 390099 \\
\hline
\end{tabular}

\begin{tabular}{|c|}
\hline 268357 \\
\hline 360891 \\
\hline 135525 \\
\hline 199318 \\
\hline 168640 \\
\hline 160399 \\
\hline 249580 \\
\hline 294387 \\
\hline 298154 \\
\hline 150142 \\
\hline 150122 \\
\hline 64680 \\
\hline 301318 \\
\hline 45122 \\
\hline 343681 \\
\hline 274313 \\
\hline 325882 \\
\hline 284502 \\
\hline 262879 \\
\hline 312368 \\
\hline 154521 \\
\hline 390516 \\
\hline 254298 \\
\hline 419636 \\
\hline 445595 \\
\hline 217528 \\
\hline 242920 \\
\hline 223540 \\
\hline 264886 \\
\hline 256737 \\
\hline 484870 \\
\hline 417031 \\
\hline
\end{tabular}


medRxiv preprint doi: https://doi.org/10.1101/2021.09.25.21264106; this version posted September 28, 2021. The copyright holder for this preprint (which was not certified by peer review) is the author/funder, who has granted medRxiv a license to display the preprint in perpetuity.

All rights reserved. No reuse allowed without permission.

Function-on-function linear model

We consider a functional input and functional output regression model where we treated $\mathrm{y}(\mathrm{t})$ as a scalar at each time $\mathrm{t}$, i.e., $x(t) \rightarrow$ $y(t)$. The functional linear model with an intercept is of the form:

$$
y(t)=\beta_{o}(t)+\int \beta(s, t) x(s) d s+\epsilon(t) .
$$

We used this method to perform a funtion-on-function linear regression on our set of functional data by using some curves to predict another set of curves while also estimating the slope $\beta(s, t)$ whose results in considered cases are presented in $3 \mathrm{D}$ diagrams of

Figure 13.

392

394

395

396

397

398

399

400

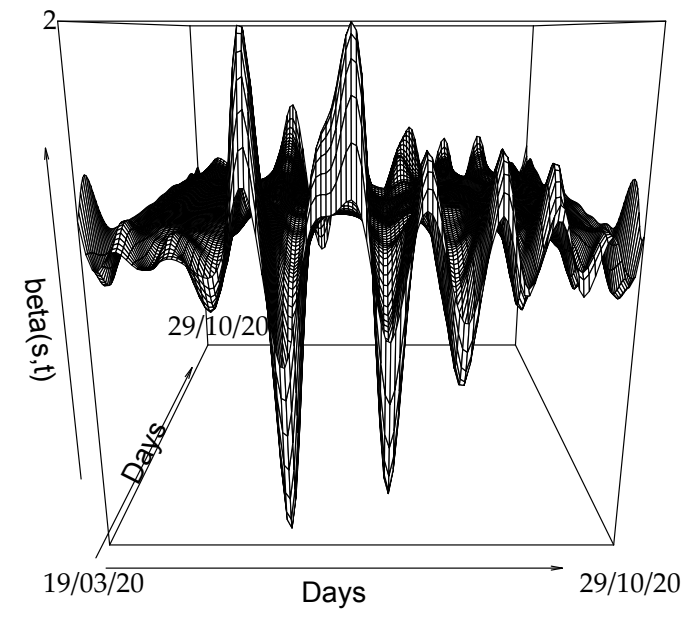

(a)

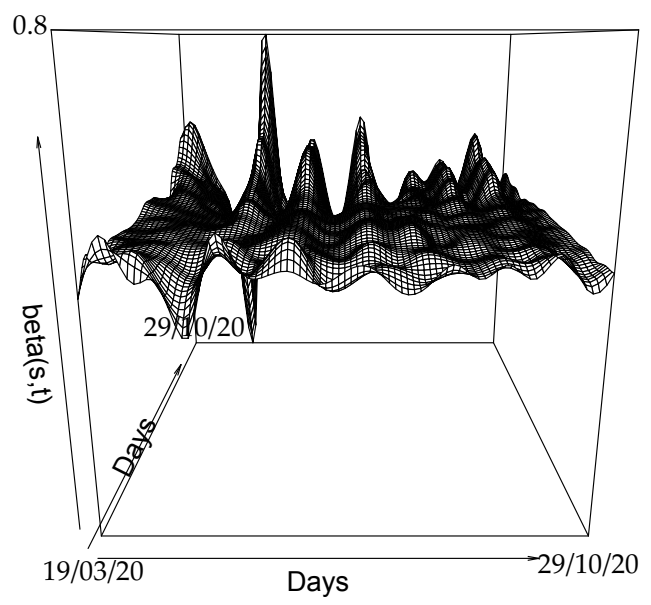

(c)

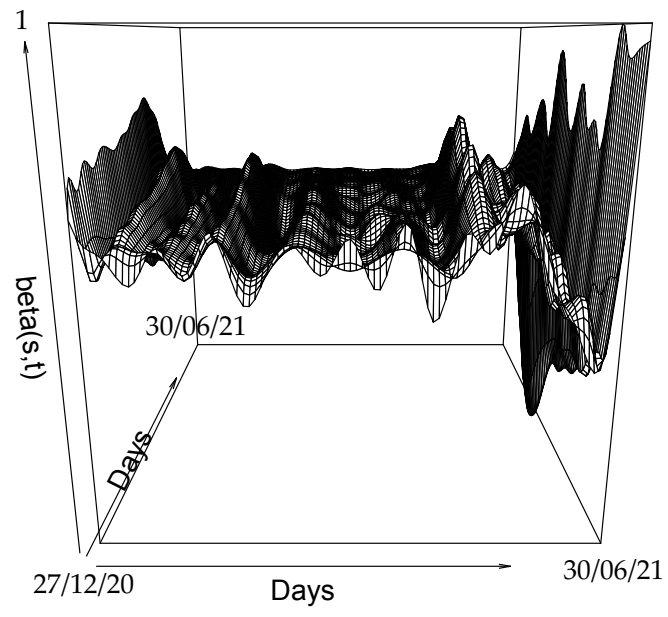

(b)

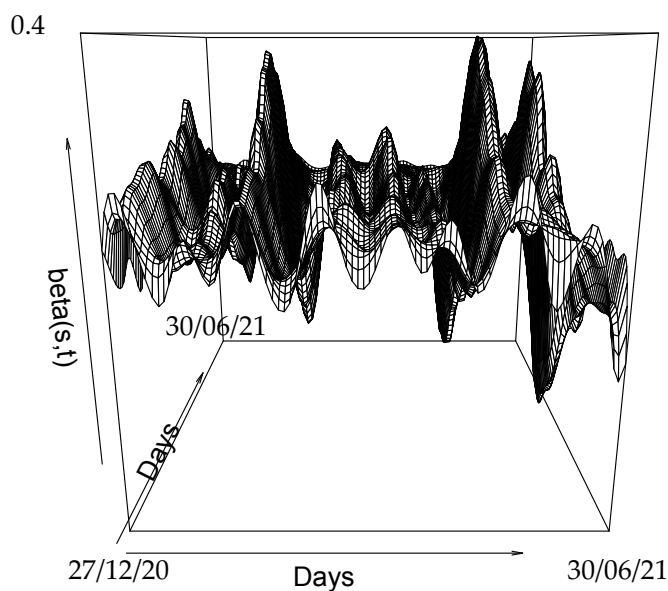

(d) 


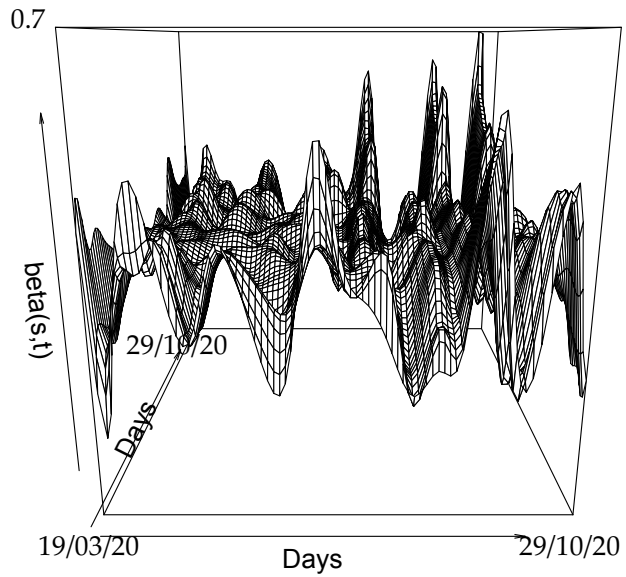

(e)

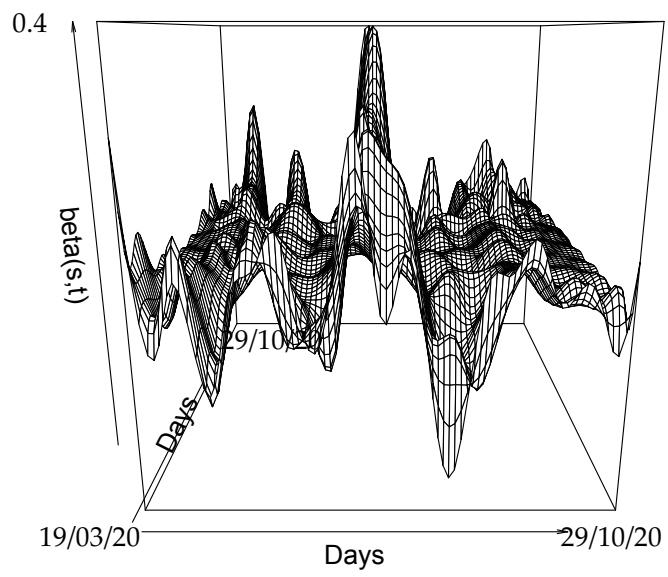

(g)

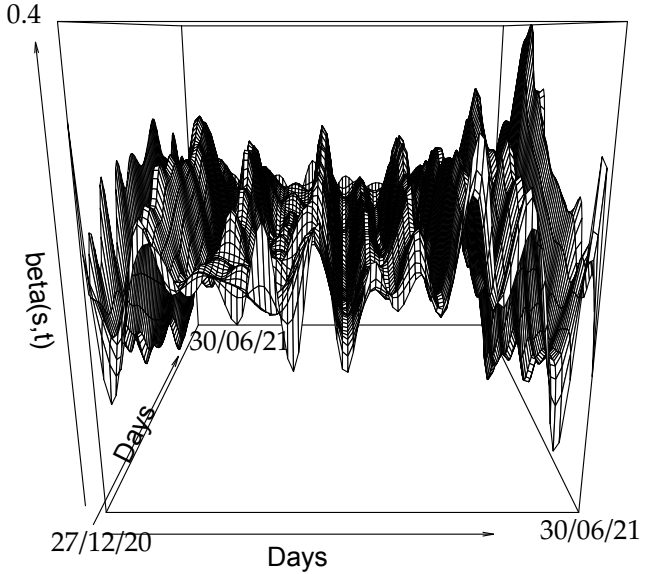

(f)

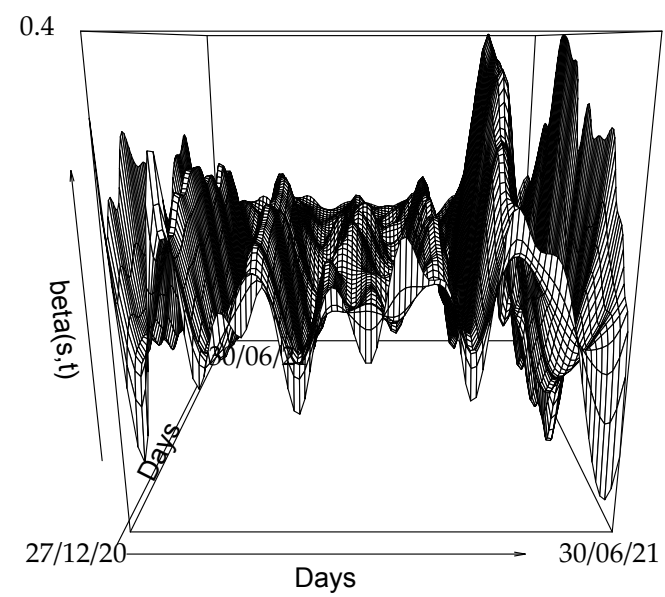

(h)

Figure 13. The 3D visualization of function-on-function regression for (a) hospitalized cases, (b) hospitalized when vaccination has started, (c) ICU cases, (d) ICU cases when vaccination has started, (e) daily return home, (f) daily return home when vaccination has started, $(\mathrm{g})$ daily deaceased and $(\mathrm{h})$ daily deaceased when vaccination has started.

Figure 13a shows hospitalized cases with the slope on the interval $-2.799063 \leq \beta(s, t) \leq 1.980147$, Figure $13 \mathrm{~b}$ shows hospitalized when vaccination has started with the slope on the interval $-1.501887 \leq \beta(s, t) \leq 1.076421$, Figure $13 \mathrm{c}$ shows ICU cases with the slope on the interval $-1.0733846 \leq \beta(s, t) \leq 0.8411007$, Figure13d shows ICU cases when vaccination has started with the slope on the interval $-0.5646148 \leq \beta(s, t) \leq 0.3661280$, Figure 13e shows daily return home with the slope on the interval $-0.6755000 \leq \beta(s, t) \leq 0.7030529$, Figure $13 \mathrm{f}$ shows daily return home when vaccination has started with 
the slope on the interval $-0.4333295 \leq \beta(s, t) \leq 0.4300995$, Figure $13 \mathrm{~g}$ shows daily deaceased with the slope on the interval $-0.3277864 \leq \beta(s, t) \leq 0.4002531$ and Figure $13 \mathrm{~h}$ shows daily deaceased when vaccination has started with the slope on the interval $-0.3284866 \leq \beta(s, t) \leq 0.3641679$. We observed that in all these Figures in this Section, the 3D surfaces yields results whose shapes look roughly similar to the slope curve, functional predictors curve and functional response curve.

\section{Perspectives and Conclusion}

We studied in this article the best way to summarize temporal information relating to the variations of variables linked to the epidemic dynamics of COVID-19, such as hospitalized cases before and after vaccination has started, medical intensive care unit (MICU) cases before and after vaccination, daily return home cases before and after vaccination, and daily deceased before and after vaccination. Using the functional principal component analysis, it was shown that the first functional principal component well summarized the $\mathrm{U}$ or $\mathrm{W}$ shape observed for the data related to the first three principal components. This discovery confirms the importance of this first component for the explanation and the qualitative prediction from the observed data. The influence of vaccination is visible, because the $\mathrm{U}$ or $\mathrm{W}$ shape is attenuated after vaccination, and does not come close to the shapes observed for seasonal influenza [16]. The subsequent functional principal components have poor predictive power, but the second component clearly shows the reducing influence of vaccination on all epidemic variables. A further, more in-depth study could undoubtedly show the predictive nature of this second component on the future success of a vaccination policy, by comparing different countries with different vaccination rates and by quantifying the phase of descent of the curves of the second component (for example by its slope at the second inflection and by the value of its minimum).

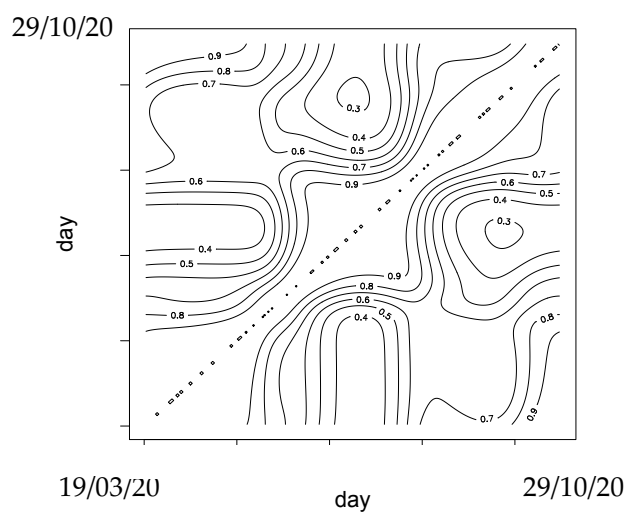

(a)

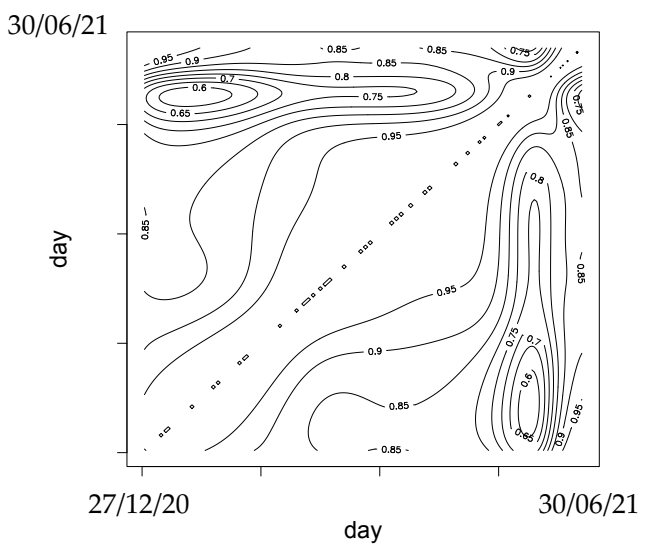

(b) 
medRxiv preprint doi: https://doi.org/10.1101/2021.09.25.21264106; this version posted September 28, 2021. The copyright holder for this preprint (which was not certified by peer review) is the author/funder, who has granted medRxiv a license to display the preprint in

perpetuity.

All rights reserved. No reuse allowed without permission.

$29 / 10 / 20$

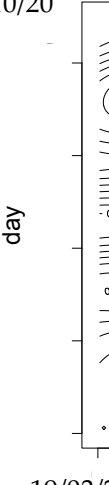

$19 / 03 / 20$

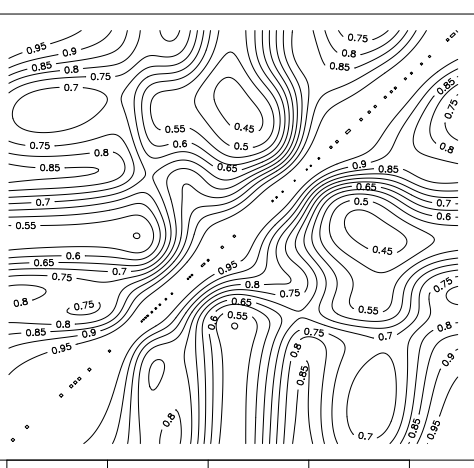

day

$29 / 10 / 20$

(c)

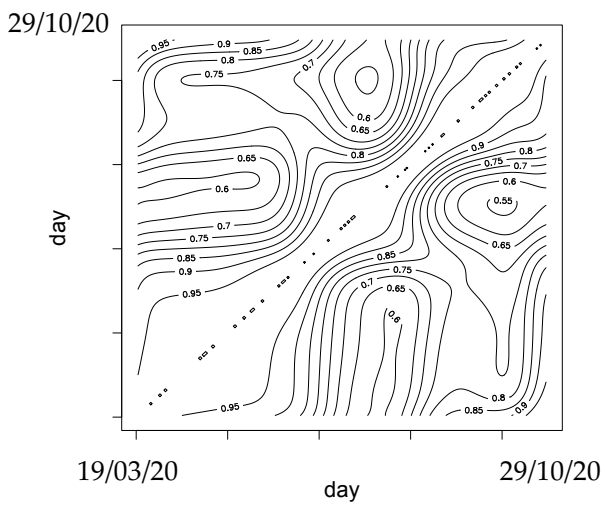

(e)

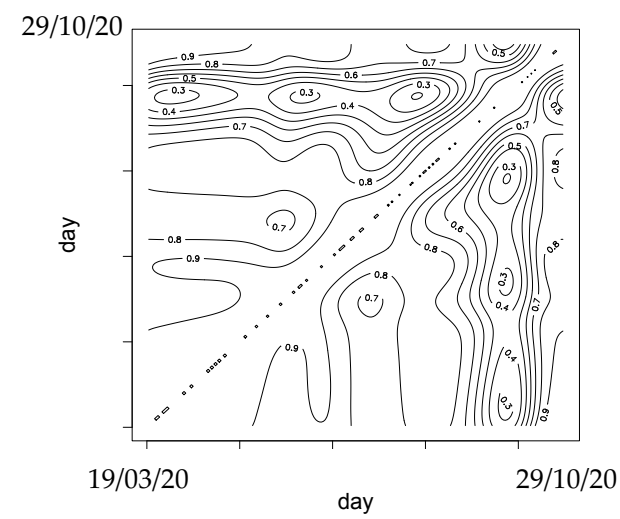

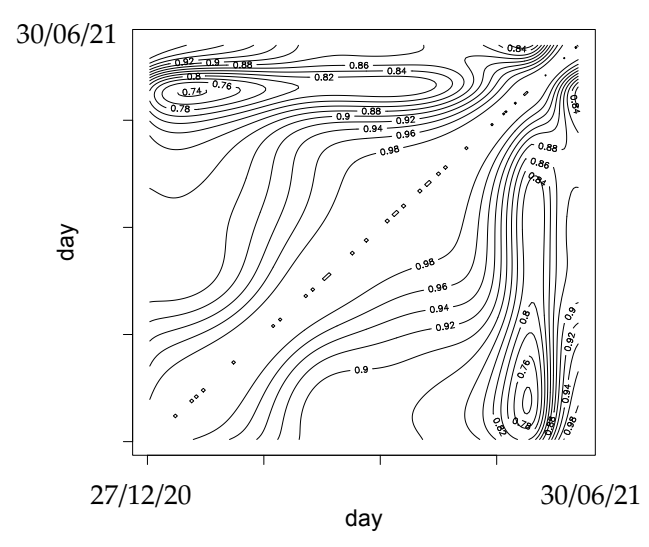

(d)

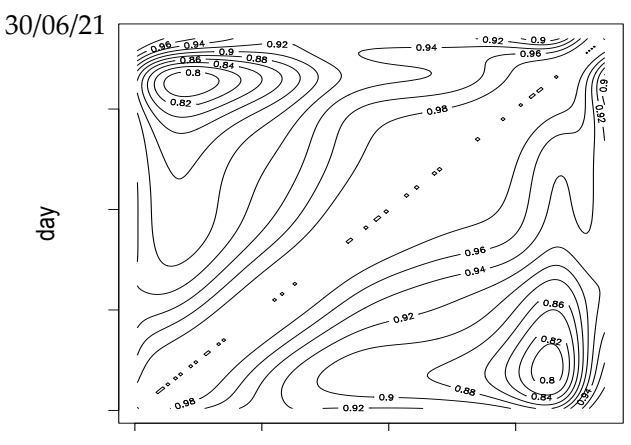

$27 / 12 / 20$

day

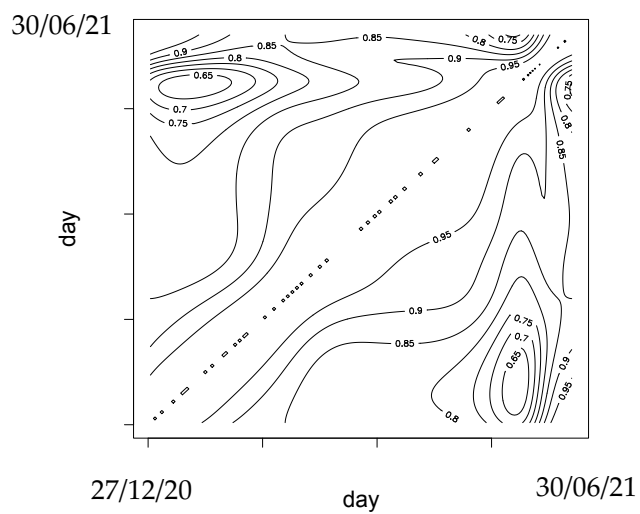

(h) 
Figure 14. Correlation coefficients between all French departments contour plot. (a) hospitalized cases, (b) hospitalized when
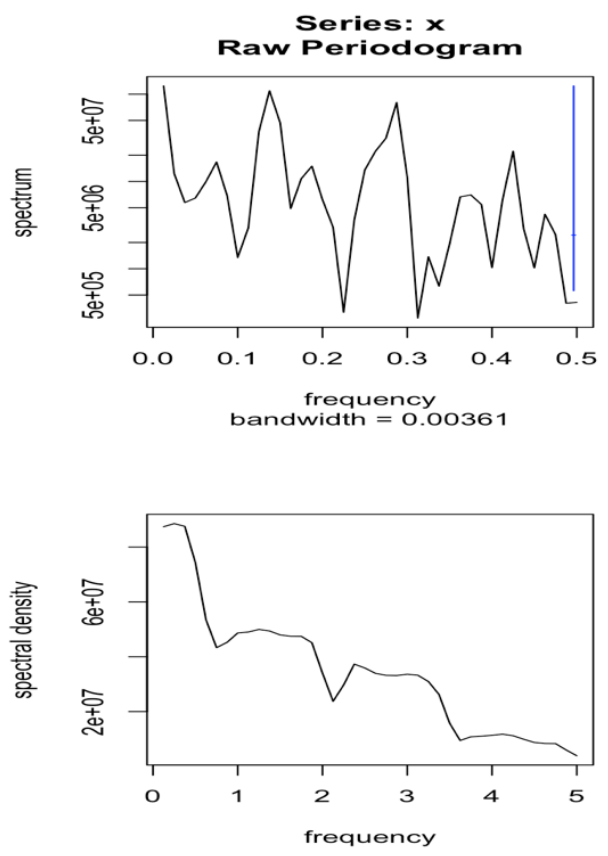

Figure 15. Spectral analysis of daily new cases between 01/05/2021 to 15/07/2021 in France.

\section{Author's contribution}

Conceptualization, J.D.; K.O. and M.R.; methodology, J.D.; K.O.; F.I. and M.R.; software, K.O. and F.I.; validation, J.D.; K.O. and M.R.; formal analysis, K.O. and F.I.; investigation, J.D. and M.R.; resources, J.D.; data curation, K.O. and F.I.; writing-original draft preparation, K.O.; writing — review and editing, J.D. and K.O; visualization, K.O. and F.I.; supervision, J.D. and M.R; project administration, J.D. and M.R. All authors have read and agreed to the final version of the manuscript.

\section{Conflict of interest}

Authors declare no conflict of interest.

\section{Funding}

No specific funding was received for this research.

\section{Acknowledgments}

The authors wish to acknowledge the Petroleum Technology Development Fund (PTDF) Nigeria doctoral fellowship in collaboration with Campus France Africa Unit. 


\section{References}

[1] Ferraty, F.; Vieu, P. Nonparametric Functional Data Analysis. Springer, 2006.

[2] Tang, C.; Wang, T.; Zhang, P. Functional data analysis: An application to COVID-19 data in the United States. arXiv, 2020, arXiv:2009.08363.

[3] Acal, C.; Escabias, M.; Aguilera, A.M.; Valderrama, M.J. COVID-19 Data Imputation by Multiple Function-on-Function Principal Component Regression. Mathematics, 2021, 9, 1237. https://doi.org/10.3390/math9111237.

[4] Tobia, B.; Jacopo, D.; Lorenzo, T.; Marzia C.; Francesca C. The shapes of an epidemic: using Functional data analysis to characterize Covid-19 in Italy. arXiv, 2020, arXiv:2008.04700v1.

[5] Tucker, J.D. Functional Component Analysis and Regression using Elastic Methods. PhD. Thesis, Florida State University, 2014.

[6] Tucker, J.D.; Wu, W.; Srivastava. Generative models for functional data using phase and amplitude separation. Computational Statistics and Data Analysis, 2013, 61, 50-66.

[7] Ramsay, J.O.; Silverman, B.W. Applied Functional Data Analysis: Methods and Case Studies. Springer, 2002.

[8] Srivastava, A.; Klassen, E. P. Functional and shape data analysis. In Functional Data and Elastic Registration. Springer, 2016, 73-122.

[9] Ramsay, J.O.; Hooker, G. Functional Data Analysis with R and Matlab. Springer.

[10] Worldometers. Available online: https://www.worldometers.info/coronavirus/ (accessed on 12 $2^{\text {th }}$ July 2021$) 2021$.

[11] https://www.data.gouv.fr/fr/datasets/donnees-hospitalieres-relatives-a-lepidemie-de-covid-19/ (accessed on 12 ${ }^{\text {th }}$ July 2021)

2021.

[12] https://covidvax.live/location/fra (accessed on 12 $2^{\text {th }}$ July 2021) 2021.

[13] Gaudart, J.; Landier, J.; Huiart, L.; Legendre, E.; Lehot, L.; Bendiane, M.K.; Chiche, L.; PetitJean, A.; Mosnier, E.; KirakoyaSamadoulougou, F.; Demongeot, J.; Piarroux, R.; Rebaudet, S. Factors associated with spatial heterogeneity of Covid-19 in France: a nationwide ecological study. The Lancet Public Health 2021, 6, e222-e231.

[14] Griette, Q.; Demongeot, J.; Magal, P. A robust phenomenological approach to investigate COVID-19 data for France. Math. Appl. Sci. Eng. 2021, 2, doi.org/10.5206/mase/14031.

[15] Ilie, O.D.; Cojocariu, R.O.; Alin Ciobica, A.; Timofte, S.I.; Mavroudis, I.; Bogdan Doroftei, B. Forecasting the Spreading of COVID-19 across Nine Countries from Europe, Asia, and the American Continents Using the ARIMA Models. Microorganisms, 2020, $8: 1158$.

[16] Tojanovic, J.; Boucher,V.G.; Boyle,J.; Enticott,J.; Lavoie,K.L. Bacon,S.L. COVID-19 is not the flu: four graphs from four countries. Frontiers in Public Health 2021, doi: 10.3389/fpubh.2021.628479. 